\title{
Carbon aerogel evolution: Allotrope, graphene-inspired, and 3D-printed aerogels
}

\author{
Swetha Chandrasekaran, Patrick G. Campbell, Theodore F. Baumann, and Marcus A. Worsley ${ }^{\text {a) }}$ \\ Lawrence Livermore National Laboratory, Livermore, California 94551, USA
}

(Received 11 July 2017; accepted 26 September 2017)

\begin{abstract}
Carbon aerogels (CAs) are a unique class of high surface area materials derived by sol-gel chemistry. Their high mass-specific surface area and electrical conductivity, environmental compatibility, and chemical inertness make them very promising materials for many applications, such as energy storage, catalysis, sorbents, and desalination. Since the first CAs were made via pyrolysis of resorcinol-formaldehyde (RF)-based organic aerogels in the late 1980s, the field has really grown. Recently, in addition to RF-derived amorphous CAs, several other carbon allotropes have been realized in aerogel form: carbon nanotubes (CNTs), graphene, graphite, and diamond. Furthermore, the popularity of graphene aerogels has inspired research into aerogels made of a host of graphene analog materials (e.g., boron nitride, transition metal dichalcogenides, etc.), with potential for an even wider array of applications. Finally, the development of threedimensional-printed aerogels provides the potential for CAs to have an even broader impact on energy-related technologies. Here, we will present recent work covering the novel synthesis of RF-derived, CNT, graphene, graphite, diamond, and graphene analog aerogels.
\end{abstract}

\section{INTRODUCTION}

Aerogels cover a class of solid materials distinguished by their extreme low density and ultrafine, open pore structure. Initially synthesized as a wet gel, aerogels are created by replacing the liquid phase of the wet gel with gas, which results in a dry porous solid. As the pore structure is minimally perturbed during this process, it is not uncommon for aerogels to consist of greater than $95 \%$ porosity, with pores that average less than $100 \mathrm{~nm}$. These features alone give aerogels in general some very unique properties, such as large accessible surface areas and extremely low thermal conductance. In fact, the first metal-oxide aerogels prepared by Kistler et al. targeted applications in catalysis ${ }^{1}$ and thermal insulation ${ }^{2}$ to take advantage of these novel properties. Aerogel research has continued to grow since Kistler et al. prepared the first aerogels in the 1930s. For the first few decades, though new synthesis routes were reported, ${ }^{3,4}$ the composition of aerogels was limited to metal oxides. However, in the past 30 years, there has been a collective push to not only develop new methods ${ }^{5}$ to produce traditional metal oxides but also to expand the variety of materials that aerogels cover. Some notable examples of these new aerogels include reports of organic aerogels, ${ }^{6}$ carbons $^{7-10}$ conducting oxides $^{11}$

Contributing Editor: Paolo Colombo

a) Address all correspondence to this author.

e-mail: worsley1@1lnl.gov

DOI: $10.1557 / j m r .2017 .411$ chalcogenides, ${ }^{12}$ metals, ${ }^{13-15}$ and various two-dimensional (2D) materials. ${ }^{16-18}$ A major driver for realizing aerogels from a wider materials set is the potential to unlock novel properties that these materials only exhibit as aerogels.

Carbon aerogels (CAs), in particular, possess a unique combination of ultralow density, large surface area, high electrical conductivity, thermal and chemical robustness, and good mechanical properties, not available in other aerogel materials. These properties arise directly from assembling amorphous $s p^{2}$ carbon nanoparticles into a highly porous, low-density aerogel. Consequently, CAs have enjoyed steady growth in research interest since their invention in the early $1990 \mathrm{~s}^{7}$ [Fig. S1(a)] and have been actively pursued for applications touching a wide variety of fields including energy storage, catalysis, filtration, chemical sensors, energy generation, sorbents, and electronics. The discovery of new carbon allotropes ${ }^{19-21}$ (e.g., nanotubes, graphene, and fullerene) has fueled pursuits to synthesize aerogels on the basis of these novel nanomaterials. Graphene aerogels (GAs) have been an exceptionally popular topic, showing a very rapid rise in published works and citations since its invention [Fig. S1(b)]. The intense interest in graphene is in part largely due to the advantages that the graphene allotrope exhibits compared with amorphous or nanocrystalline carbon. Furthermore, graphene has inspired interest in other 2D materials, such as boron nitride (BN), transition metal dichalcogenides, and black phosphorus (BP). This interest in graphene-inspired materials has also 
led to novel synthesis routes to make aerogels based on these 2D materials. And finally, CAs have been playing a prominent role in the emerging body of literature devoted to three-dimensional (3D)-printed aerogels. This has led to the development of novel 3D printing schemes to make aerogel synthesis compatible with current 3D printing technologies. Conventional CAs have been covered in previous reviews, but a broad look at how the CA synthesis has evolved and expanded the aerogel landscape is lacking. ${ }^{22-26}$ Therefore, this review seeks to provide the reader with a survey of the CA synthesis methods with a focus on novel carbon allotropes, graphene-inspired or 2D materials, and 3D printing, as well as some perspective with regard to the future outlook for aerogel synthesis.

\section{CARBON ALLOTROPES}

Allotropes refer to the different forms of a chemical element, which may possess very different properties. As such, aerogels of the various allotropes would also be expected to reflect these different properties. In the case of carbon, aerogels based on four different carbon allotropes have been reported: (i) amorphous carbon, (ii) carbon nanotubes (CNTs), (iii) diamond, (iv) graphite, and (v) graphene. ${ }^{27}$ Following is a discussion of the synthesis methods, properties, and applications of each of these important CAs.

\section{A. Amorphous carbon}

Traditional CAs consist of a 3D network of interconnected amorphous carbon nanoparticles. Because of their high surface area, mechanical robustness, and electrical conductivity, they have been widely pursued for electrical energy storage, hydrogen storage, desalination, and catalysis. CAs were originally derived from organic aerogels synthesized via the polycondensation of resorcinol with formaldehyde. ${ }^{6}$ These resorcinol-formaldehyde (RF) aerogels were then fired under inert gas to produce RF-derived CAs (Fig. 1). This RF sol-gel route to $s p^{2}$-hybridized carbon gels was a key development in the evolutionary path of CAs. Specifically, the scheme of starting with a carbon precursor in solution (or suspension), inducing gelation (e.g., cross-linking, solidification, etc.), and then converting the precursor to the desired carbon allotrope is a pattern that will be apparent in many of the methods used to synthesize the carbon allotrope aerogels. And in some cases, the organic sol-gel

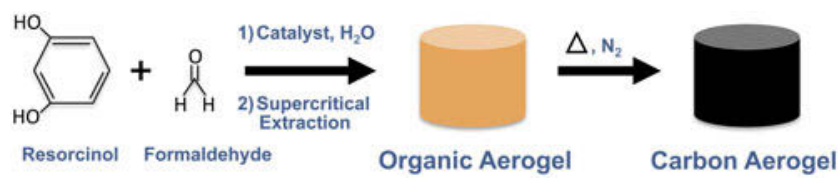

FIG. 1. Synthesis scheme for resorcinol-formaldehyde sol-gel path to CAs. method is directly utilized to assist in building the matrix of other carbon allotrope aerogels.

\section{B. CNT aerogel}

CNTs possess exceptional mechanical, thermal, and electrical properties. ${ }^{23}$ Therefore, structures fabricated from these materials hold technological promise for a variety of applications, ${ }^{8,28-34}$ including structural composites, thermal interfaces, energy storage, actuators, and artificial membranes. Synthesizing CNT aerogels that retain the intrinsic properties of individual tubes, however, is extremely challenging. In general, CNT aerogel synthesis begins with a dispersion of CNTs. Although there are a few examples where CNTs are grown within an aerogel matrix ${ }^{35-38}$ they are the exception. Pristine CNTs, being hydrophobic, require a surfactant if dispersal in aqueous media is required. Otherwise, organic solvents or highly oxidized CNTs must be used. Next, gelation is induced via a physical or chemical cross-linking mechanism, followed by drying [typically freeze drying or critical point drying (CPD)], and any desired post-processing.

Bryning et al. reported the first CNT aerogel in 2007. Bryning et al. used a surfactant to successfully disperse a low concentration of single-walled CNTs (SWCNT) in water. The suspension would form a physical gel overnight and then be washed in water or an aqueous polyvinylalcohol (PVA) solution to remove surfactant and, in the case of the PVA solution, mechanically reinforce the aerogel. Both freeze-drying and CPD were used to achieve the final aerogel (Fig. 2). The final properties of the CNT aerogel (e.g., electrical conductivity, mechanical robustness, and density) were highly dependent on the CNT concentration, PVA concentration, and drying method. CPD was shown to give consistently better results overall than freeze-drying, and increasing CNT concentration gave electrical conductivities as high as $1 \mathrm{~S} / \mathrm{cm}$ when no PVA was used. This is quite remarkable given that a traditional CA of equal density would be expected to exhibit an order of magnitude lower conductivity. However, the pure CNT aerogels were fragile because they rely solely on van der Waals (physical) forces between CNTs for mechanical integrity. Alternatively, the PVA-reinforced CNT aerogel exhibited remarkable mechanical integrity by supporting 8000 times its own weight but suffered from low conductivity as the binder likely interferes with electrical conduction between CNTs. Regardless, this work provided the first evidence of the enhanced properties that could be realized in a CNT aerogel and led to many more notable works. ${ }^{16,39,40}$

To produce CNT aerogels with both the desired mechanical and electrical properties, some researchers sought to mechanically reinforce the CNTs with a conductive binder instead of the traditional polymer binder. The RF sol-gel route is a natural choice for such an 


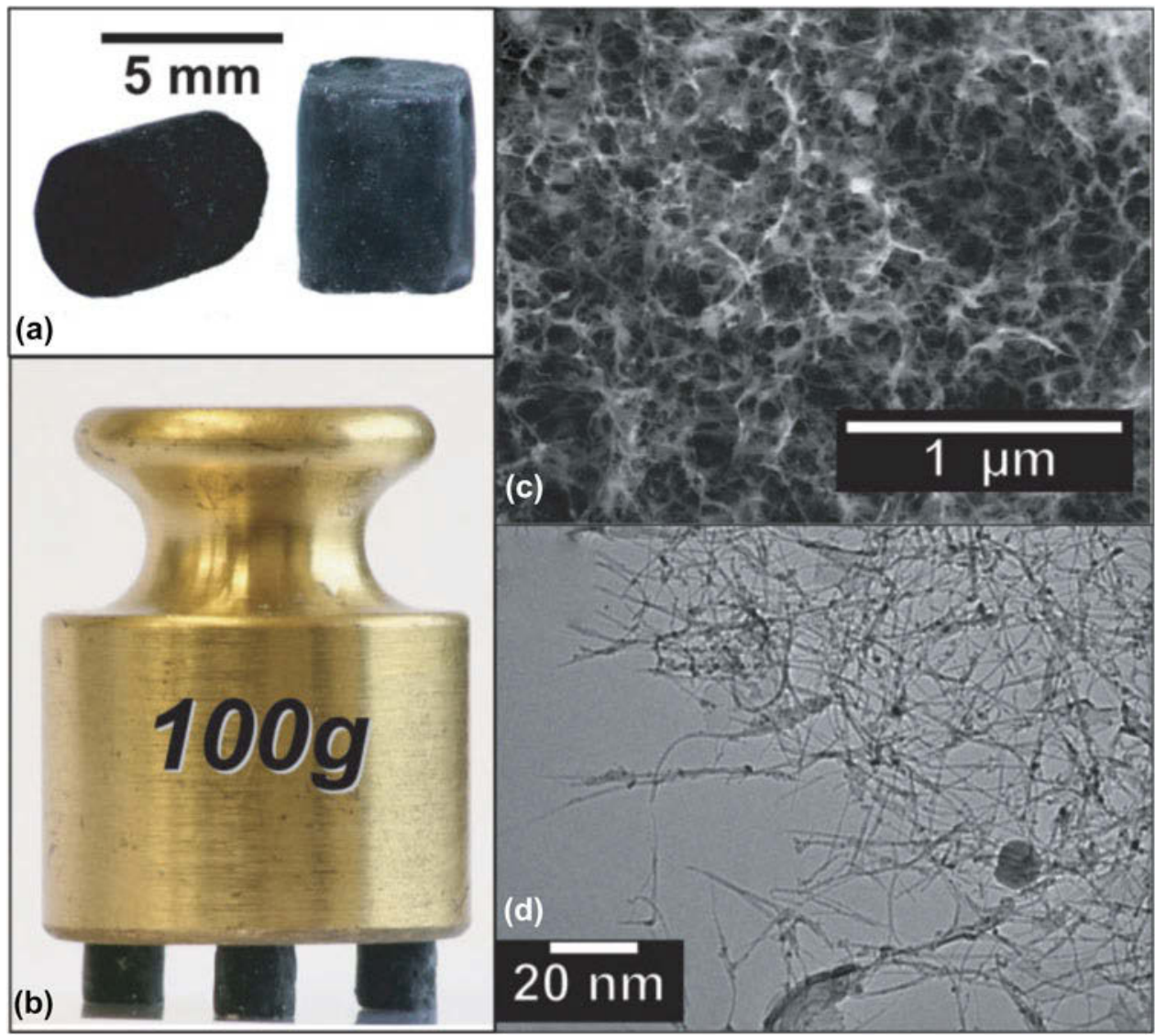

FIG. 2. Images of aerogels. (a) Macroscopic pieces of $7.5 \mathrm{mg} / \mathrm{mL}$ CNT aerogels. Pristine CNT aerogel (left) appears black, whereas the aerogel reinforced in a $1 \mathrm{wt} \%$ PVA bath (right) is slightly gray. (b) Three PVA-reinforced aerogel pillars (total mass $=13.0 \mathrm{mg}$ ) supporting $100 \mathrm{~g}$, or approximately 8000 times their weight. (c) This SEM image of a critical-point-dried aerogel reinforced in a $0.5 \mathrm{wt} \%$ PVA solution $(\mathrm{CNT}$ content $=$ $10 \mathrm{mg} / \mathrm{mL}$ ) reveals an open, porous structure. (d) This high-magnification TEM image of an unreinforced aerogel reveals small-diameter CNTs arranged in a classic filamentous network. Reproduced by permission from Ref. 8 (John Wiley and Sons).

effort. During the initial efforts by Worsley et al., ${ }^{41}$ a small concentration of the surfactant-dispersed CNTs was added to the traditional RF solution before gelation, aiming to achieve a homogenous dispersion of CNTs within the aerogel framework. After gelation, drying, and carbonization, a CNT-CA composite was observed via electron microscopy. For the CNT-CA, instead of observing a network consisting solely of amorphous carbon nanoparticles, the CNTs were uniformly dispersed as bundles within the CA matrix. Not surprisingly, the CNT-CAs prepared with higher CNT concentrations showed a higher population of CNTs in the images. The CNT-CAs also showed enhanced electrical and mechanical properties. ${ }^{41}$ However, as the proportion of RF-derived carbon was still relatively high compared with the CNT fraction, the improvements were not as significant as those reported by Bryning et al. To minimize the amount of RF-derived carbon, such that its presence in the CNT aerogel was limited to coating and cross-linking the CNT network, another study by Worsley et al. ${ }^{42}$ reduced the RF concentration in the sol-gel reaction mixture from 12 to $4 \mathrm{wt} \%$ while holding the CNT concentration constant. By introducing low concentrations of the sol-gel precursors to a suspension of highly purified CNTs, polymerization is induced primarily on the walls of the CNT bundles and, more importantly, at the junctions between adjacent bundles to form an organic binder. Upon carbonization, the organic binder is reduced to a conductive, mechanically reinforcing $s p^{2}$ carbon binder. Scanning electron microscopy (SEM) showed that the network of CNT-based foams comprises randomly interconnected filament-like struts with diameters that range from 5 to $40 \mathrm{~nm}$ and lengths of $\sim 500-1000 \mathrm{~nm}$ (Fig. S2). Transmission electron microscopy (TEM) showed that at the surface, these filaments do not appear to be simply individual CNTs or CNT bundles as the nanotube walls are not visible. The CNTs were coated with a thin layer of carbon, indicating that nucleation and growth of the sol-gel polymer did indeed occur on the surfaces of the CNTs.

The utilization of the carbonaceous binder affords monolithic CNT aerogels that simultaneously exhibit exceptional mechanical and electrical properties. In Fig. 3, the elastic moduli of these CNT aerogels are compared with some other porous carbon materials, such 


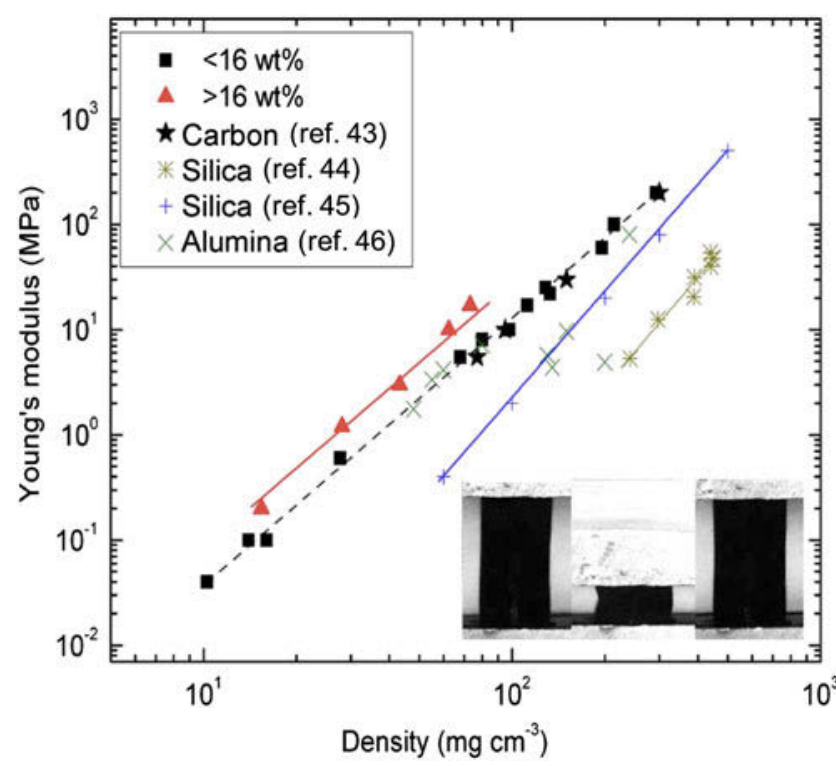

FIG. 3. Dependence of Young's modulus on density for monolithic CNT foams compared to carbon, silica, and alumina aerogels. The inset shows the sequence of uniaxial compression of a monolith $30 \mathrm{mg} / \mathrm{cm}^{3}$ and $55 \mathrm{wt} \% \mathrm{CNT}$ content, illustrating the superelastic behavior with complete strain recovery after compression to strains as large as $76 \%$. Reproduced by permission from Ref. 42 (American Institute of Physics).

as conventional CAs, highlighting the unprecedented mechanical properties of CNT-based aerogels. Indeed, for a given density, the CNT-based aerogel is the stiffest. In fact, at a density of $100 \mathrm{mg} / \mathrm{cm}^{3}$, aerogels with high CNT loadings (over $16 \mathrm{wt} \%$ ) are $\sim 12$ and $\sim 3$ times stiffer than conventional silica and CAs, respectively. ${ }^{43-45}$ These CNT-based aerogels are also $\sim 3$ times stiffer than the "super-stiff" alumina nanofoams whose struts have the morphology of curled nanoleaflets. ${ }^{46}$ The inset in Fig. 3 shows a sequence of images taken of an $\sim 30 \mathrm{mg} / \mathrm{cm}^{3}$ aerogel with a CNT loading of $55 \mathrm{wt} \%$ before, during, and after uniaxial loading up to a maximum strain of $\sim 76 \%$, showing the "superelastic" behavior with complete strain recovery that has been observed for nanotube-based aerogels with densities below $\sim 50 \mathrm{mg} / \mathrm{cm}^{3}$. In addition to exceptional mechanical properties, these low-density CNT aerogels also exhibit a 5-fold increase in electrical conductivity $(>1 \mathrm{~S} / \mathrm{cm})$ compared with standard CAs.

Gutiérrez et al. ${ }^{47}$ achieved enhanced performance in CNT-based aerogels by adapting the organic sol-gel method to deep eutectic solvents (DESs) that readily disperse CNTs. Gutiérrez et al. report that DESs catalyze the polycondensation of furfuryl alcohol to form a bicontinuous porous architecture consisting of colloidal particles. On inclusion of multiwalled CNT (MWCNT), it appears that furfuryl alcohol preferentially coats the MWCNTs forming a strong, conductive "glue" between the MWCNTs after carbonization (Fig. S3). This carbon shell resulted in CNT-based aerogels with electrical conductivities as high as $4.8 \mathrm{~S} / \mathrm{cm}$ and elastic moduli up to $24 \mathrm{MPa}$. Thus by using the RF sol-gel method to form $s p^{2}$ carbon junctions between CNTs, CNT aerogels that simultaneously exhibited good electrical conductivity and mechanical robustness were realized. ${ }^{42,47,48}$

Recently, De Marco et al. ${ }^{49}$ demonstrated another route to synthesis of CNT aerogels with covalent carbon bonds starting from SWCNT anions in $N, N$-dimethylacetimide (DMAc). A major advantage of working with SWCNT anions in DMAc is that one can start with a true solution of individualized CNTs at high concentrations without damaging the CNTs with sonication or oxidation. De Marco et al. then used $\mathrm{Na} /$ naphthalene as a charge transfer agent and $p$-diiodobenzene as the dielectrophilic cross-linker to create carbon-bonded CNT gels (Fig. S4). After freeze-drying, the CNT aerogels exhibited surface areas in excess of $700 \mathrm{~m}^{2} / \mathrm{g}$ and electrical conductivities of $9.4 \mathrm{~S} / \mathrm{m}$ at an ultralow density of $2.3 \mathrm{mg} / \mathrm{cm}$.

Other chemical cross-linkers have also been used to synthesize CNT aerogels with enhanced properties. Kohlmeyer et al. used ferrocene-grafted poly ( $p$-phenyleneethynylene) (Fc-PPE) to form a stable CNT gel. ${ }^{50}$ On drying via CPD and thermal annealing, in addition to exhibiting good mechanical and electrical properties, these CNT aerogels also had surface areas approaching $700 \mathrm{~m}^{2} / \mathrm{g}$. Similarly, Zou et al. ${ }^{51}$ used poly(3-(trimethoxysilyl)propyl methacrylate) to disperse and chemically cross-link a low concentration of MWCNT. The subsequent MWCNT aerogel showed excellent compressibility and high surface area. In lieu of thermal annealing, it was shown that pulsing a high electrical current through the MWCNT aerogel was sufficient to increase its electrical conductivity to $0.67 \mathrm{~S} / \mathrm{cm}$ without significantly degrading the structure. ${ }^{50}$

Finally, a number of bio-related molecules have been effectively used to synthesize CNT aerogels. Chitosan (CHI) was an effective dispersant for generating homogenous, stable MWCNT suspensions (2-8 wt $\%)$. ${ }^{52}$ Using a process called ice segregation-induced self-assembly (ISISA), the suspensions are unidirectionally frozen via immersion in liquid nitrogen and freeze-dried. The final MWCNT/CHI aerogels are highly porous, electrically conductive, and possess well-aligned microchannels, which can be controlled by freezing rate, direction, and MWCNT concentration (Fig. S5). Kwon et al. ${ }^{53}$ also utilized ice templating to create MWCNT aerogels. In this case silk fibroin was used as the structural binder. Non-aligned aerogels were formed by flash freezing the silk-fibroin-gelled MWCNT suspensions, whereas unidirectional freezing was used for the aligned aerogels. The aligned MWCNT aerogels exhibited orders of magnitude higher electrical conductivity than the nonaligned aerogels. Lastly, Ostojic ${ }^{55}$ introduced a streptavidin/DNA connector 
to noncovalently bind SWCNTs into ultra-lightweight aerogels with densities as low as $0.75 \mathrm{mg} / \mathrm{cm}^{3}$.

As seen in the above examples, the synthesis methods play a critical role in determining the observed properties of a CNT aerogel. The CNT-to-CNT cross-links can be covalent or noncovalent; binder and CNT fraction can vary greatly; and the drying method can play a crucial in the pore morphology. Nonetheless, it has been shown repeatedly that the extraordinary properties of individual CNTs can be realized in CNT aerogels if the correct synthesis scheme is chosen. With this wide variety of viable routes to high performance CNT aerogels comes the ability to customize the CNT aerogel for the rigors of specific applications.

\section{Graphene aerogels}

Individual graphene sheets possess a number of remarkable properties, including extremely low electrical and thermal resistivity, ${ }^{55}$ large carrier mobility, ${ }^{56}$ high surface area, ${ }^{57}$ and exceptional mechanical elasticity. ${ }^{58}$ Graphene and graphene-based materials hold technological promise in the areas of energy storage, ${ }^{59,60}$ electronics, ${ }^{61,62}$ composites, ${ }^{63}$ actuators, ${ }^{64}$ and sensors. ${ }^{65,66}$ Realizing the full potential of graphene in these applications, however, requires the design of bulk multifunctional architectures that retain the exceptional properties of graphene. Broadly speaking, the synthetic scheme for GAs is similar to that for CNT aerogels except for a few key differences. Graphene oxide (GO) is by far the most common precursor for GAs due to its affordability and ease of processing. Large-scale production of $\mathrm{GO}$ is enabled through chemical exfoliation of graphite through a well-established chemical process developed by Brodie, ${ }^{67}$ and later modified by Hummer and Offeman. ${ }^{68}$ The method is based on the principle of oxidizing graphite by treating graphite in a mixture of strong acids (such as $\mathrm{H}_{2} \mathrm{SO}_{4}$ ) and oxidizing agents (such as $\mathrm{NaNO}_{2}$ and $\mathrm{KMnO}_{4}$ ) for $2 \mathrm{~h}$ at a temperature of $45^{\circ} \mathrm{C}$. After the completion of the reaction, the mixture is then washed in an ice bath with hydrogen peroxide to remove the residual $\mathrm{KMnO}_{4}$. The presence of several functional groups such as epoxide, hydroxyl, carboxylic acid, etc., makes GO hydrophilic, and thus it can be easily dispersed in water and further exfoliated via sonication. At this point, the individual layers are negatively charged and therefore restacking of the sheets is inhibited. The layer spacing of natural graphite is $3.34 \AA$ but for GO the spacing is increased to $7.88 \AA$, which is due to the presence of water molecules and various other oxide groups. As was the case with CNT aerogels, there are limited examples of chemical vapor deposition (CVD) GA growth, but they are the exception. ${ }^{69}$ Unlike CNTs, GO is readily dissolved or suspended in aqueous media making it relatively easy to work with and more environmentally friendly. Because of the high degree of oxidation and lattice defects present in GO (i.e., $s p^{3}$ carbon) compared with CNTs, a reduction step (e.g., chemical or thermal) is required to recover the desired graphene-like (i.e., $s p^{2}$ carbon) properties. Apart from these differences, the general gelation strategies (e.g., covalent vs noncovalent) for GAs are analogous to what is reported for CNT aerogels.

In $2010, \mathrm{Xu}$ et al. $^{70}$ and Worsley et al. ${ }^{9}$ both independently reported synthesis routes for GAs. $\mathrm{Xu}$ et al. reported a hydrothermal method in which an aqueous GO suspension is heated to $180{ }^{\circ} \mathrm{C}$ in a pressure vessel for $12 \mathrm{~h}$ to simultaneously reduce and gel the GO. Gelation occurs because the oxygen functionality that imparts GO its hydrophilicity and electrostatic repulsion effect is removed upon reduction. As local regions on the GO sheet become hydrophobic, they are prone to noncovalent bonding (e.g., $\pi-\pi$ stacking) with reduced regions on nearby sheets building a physically cross-linked gel. Properties of the aerogel, accomplished via freezedrying, were strongly dependent on the starting GO concentration of the suspension. If the concentration dropped below $1 \mathrm{mg} / \mathrm{mL}$, no gel was formed. The duration of the hydrothermal treatment also proved to be critical to the properties of the aerogel. The time at elevated temperature and pressure determined the degree of reduction, which impacted density, conductivity, and cross-linking (Fig. S6). This GA demonstrated electric conductivity (up to $5 \mathrm{mS} / \mathrm{cm}$ ), good thermal stability, and mechanical properties comparable to chemically crosslinked polymer hydrogels. As such, this was a promising example of manifesting the properties of graphene sheets in an aerogel form and inspired a number of related studies. ${ }^{71-73}$ Worsley et al. used a strategy of RF sol-gel chemistry to form carbonaceous "glue" between graphene sheets in the aerogel. Much like the scheme used for the CNT aerogel, a small concentration of the RF sol-gel reactants was added to a $10 \mathrm{mg} / \mathrm{mL} \mathrm{GO}$ suspension. The RF particles preferentially nucleate and grow on the surface and between GO sheets, covalently binding them together. Thermal treatment at $1050{ }^{\circ} \mathrm{C}$ under inert gas converted both the RF and the GO to $s p^{2}$ carbon (Fig. 4). It was determined that aerogel properties such as density, surface area, and conductivity were correlated with the RF concentration. ${ }^{74}$ Electrical conductivities for this covalently bonded GA were as high as $1 \mathrm{~S} / \mathrm{cm}$ and surface areas ranged from 500 to $1200 \mathrm{~m}^{2} / \mathrm{g}$. Lim et al. ${ }^{75}$ drastically reduced the time for GA synthesis using the RF cross-linking strategy by adapting the fast gelation method developed by Mulik et al. ${ }^{76}$ The fast gelation method uses a one-pot synthesis route to prepare GO-RF gels in just a few hours instead of days. First, GO is suspended in acetonitrile, instead of water, via sonication. Then, after adding RF, hydrochloric acid is used to catalyze the sol-gel transition. Using this method, gel 
times as low as $30 \mathrm{~min}$ were achieved at $45{ }^{\circ} \mathrm{C}$. After aging for just $1 \mathrm{~h}$, the wet GO-RF gels can be washed and supercritically dried. Pyrolysis at $1000{ }^{\circ} \mathrm{C}$ is used to convert the RF to $s p^{2}$ cross-links creating a low-density, high surface area, electrical conductive GA (Fig. 5).

Other cross-linkers have also been used to synthesize GAs. Tang et al. ${ }^{77}$ reported a noble metal-promoted selfassembly of GO gels. Their method involved using glucose to reduce a metal salt (e.g., chlorides of $\mathrm{Au}$, $\mathrm{Ag}, \mathrm{Pd}, \mathrm{Ir}, \mathrm{Rh}$, or Pt, etc.) dissolved in a GO suspension to metal nanoparticles which formed critical cross-links between GO sheets. The critical role of the noble metal nanoparticles was demonstrated by dissolving the metal in aqua regia, which caused the integrity of the aerogel to degrade. Aerogels made without the metal cross-linkers were stable in aqua regia. Tang et al. also report high electrical conductivities and good mechanical strength. $\mathrm{Xu}$ et al. reported the use of DNA to cross-link GO sheets. ${ }^{78}$ In this example, a solution of double-stranded DNA (dsDNA) is added to a GO suspension and heated

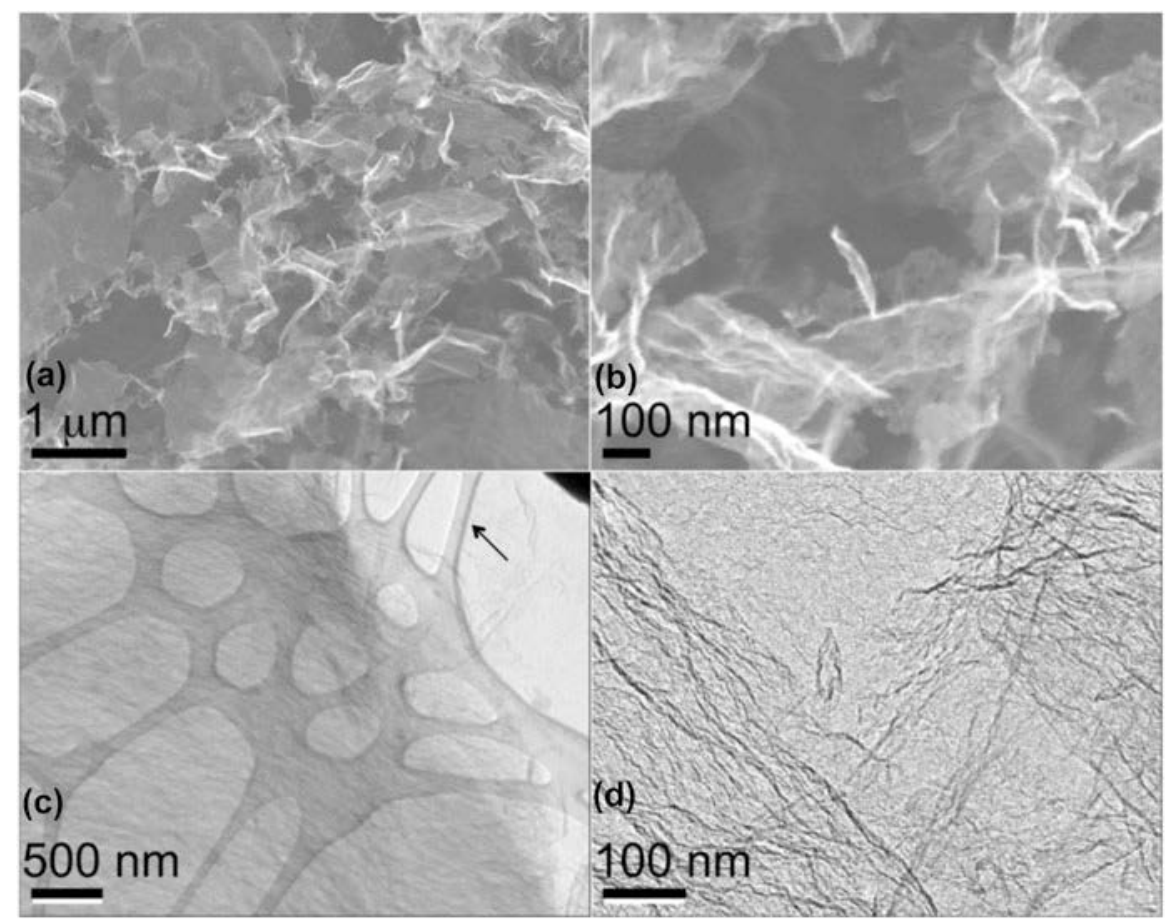

FIG. 4. SEM of the GA at low (a) and high (b) magnifications. TEM of the GA at low (c) and high (d) magnifications. Black arrow denotes holey carbon on TEM grid. Reproduced by permission from Ref. 9 (American Chemical Society).

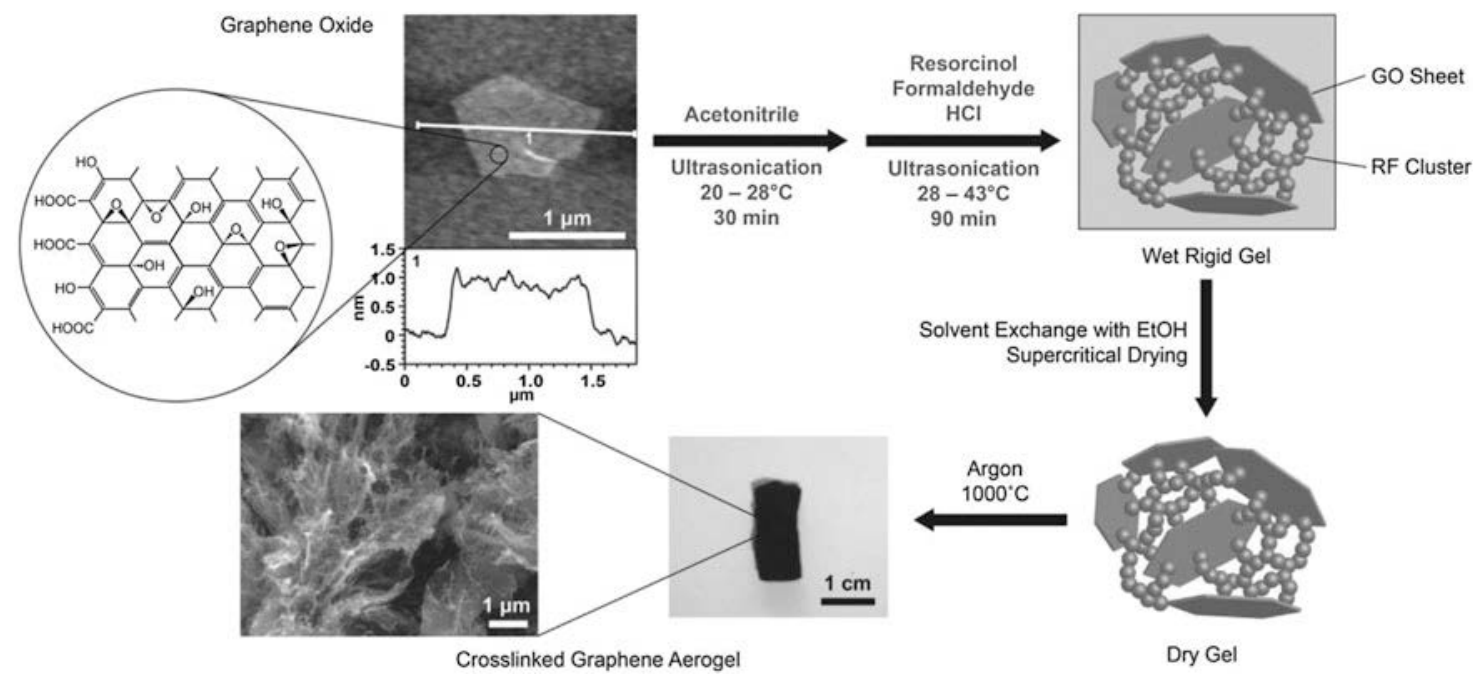

FIG. 5. Diagram of the fast GA preparation process. Reproduced by permission from Ref. 75 (Elsevier). 
to $90{ }^{\circ} \mathrm{C}$ for $5 \mathrm{~min}$. The elevated temperature causes the dsDNA to unwind to single-stranded DNA chains which form noncovalent bonds between GO sheets. Despite relying primarily on physical cross-linking for structural integrity, these GO/DNA gels showed remarkable chemical resistance and mechanically strength. Shi et al. ${ }^{79}$ used glutathione to serve both as the cross-linker and reducing agent, yielding GAs that were doped with nitrogen and sulfur.

In addition to inducing gelation using noncovalent and chemical cross-linkers, many researchers have taken advantage of the rich chemical functionality native to GO to induce self-assembly of GO suspensions. ${ }^{80,81}$ A strong base, such as ammonium hydroxide, has been shown to induce self-assembly of GO suspensions with cross-linking analogous to that found in RF sol-gel chemistry. In a recent study, ${ }^{82}$ nuclear magnetic resonance (NMR) was used to follow GO self-assembly in the presence of ammonium hydroxide at $85{ }^{\circ} \mathrm{C} .{ }^{13} \mathrm{C}$ and ${ }^{1} \mathrm{H}$ NMR spectra showed the appearance of $s p^{3}$ carbon as well as $-\mathrm{CH}_{2}$ - and $\mathrm{CH}_{2} \mathrm{O}$ - cross-linkers after gelation of the GO suspension, strongly suggesting some covalent bonding between GO sheets during gelation (Fig. S7). After annealing, these aerogels showed very high electrical conductivities $(100 \mathrm{~S} / \mathrm{m})$, were supercompressible, and possessed surface areas greater than $1300 \mathrm{~m}^{2} / \mathrm{g}$.

Several researchers have also shown that a number of chemical reducing agents can aid in the self-assembly process similar to that observed by $\mathrm{Xu}$ et al. ${ }^{70}$ with the hydrothermal treatment. In general, the self-assembly mechanism involves the aggregation of partially reduced GO sheets as their hydrophobicity increases. The sheets stack randomly as the aggregates are formed and water is expelled from the 3D assembly of aerogels, resulting in volume shrinkage of the gel. A number of chemical reagents, such as $\mathrm{NaHSO}_{3}, \mathrm{Na}_{2} \mathrm{~S}$, ethylenediamine, ammonia, HI, and hydroquinone, were used to induce GO gelation. ${ }^{83,84}$ As many chemical reducing agents are dangerous and toxic to the environment, there has been significant effort to work with "green" reducing agents, such as ascorbic acid. Zhang et al., ${ }^{85}$ as well as a number of other groups, ${ }^{86-88}$ have used ascorbic acid (e.g., vitamin C) to induce $\mathrm{GO}$ gelation. In addition to its environmentally friendly nature, it is also mild enough not to produce gaseous products, as occurs with some stronger reducing agents, which tend to disrupt or completely destroy the integrity of the gel. Zhang et al. reported that using ascorbic acid, uniform well-formed aerogels could be created with the expected enhancements in mechanical and electrical properties. Ji et al. ${ }^{71}$ used carbohydrates (glucose, $\beta$-cyclodextrin, and chitosan) as both reducing and morphology-orienting agents in the assembly of GAs. Other "green" reductants that have been reported include tannic acid, dopamine, and amino acids. ${ }^{89-91}$
In another study, ${ }^{92}$ GAs with densities less than $3 \mathrm{mg} / \mathrm{cm}^{3}$ were assembled in a one-pot synthesis step at the oil-water interface of a GO emulsion (Fig. S8). The GO emulsion was prepared using a cyclohexane/water mixture in the presence of sodium bisulfite under ultrasonication. The GO-stabilized emulsion gelled at $70{ }^{\circ} \mathrm{C}$ over $12 \mathrm{~h}$ by gradually removing the oxide functionalities. Here, sodium bisulfite acts as both reducing agent and a coemulsifier due to the salt effect. ${ }^{93}$ This method produced a cellular pore morphology which enhanced the mechanical robustness of the aerogel. Finally, $\gamma$-ray irradiation was used by He et al. ${ }^{94}$ for self-assembly of porous honeycomb GAs. A low-concentration $(5 \mathrm{mg} / \mathrm{mL})$ GO dispersion in isopropanol was deoxygenated using nitrogen gas and then irradiated with ${ }^{60} \mathrm{C} \gamma$-rays. The $\gamma$-rays induce reduction of GO, which leads to selfassembly as the $\pi-\pi$ conjugation is restored. After freezedrying, the final reduced GO aerogel has an average density of $3.8 \mathrm{mg} / \mathrm{cm}^{3}$.

Reduction of GO aerogels to GAs is done by heat treatment, chemical reagents, and by hydrothermal processing in an autoclave. ${ }^{95}$ The most commonly used chemical reagents are hydrazine, borohyrides, aluminum hydrides, and hydrohalic acids. Sudeep et al. ${ }^{96}$ reported a controlled reduction process to reduce a $3 \mathrm{D}$ covalently interconnected GO with a resorcinol-gluteraldehyde network using hydrazine monohydrate vapor at $50{ }^{\circ} \mathrm{C}$ under vacuum for $12 \mathrm{~h}$. The reduced GO had an electrical conductivity of $3.4 \mathrm{~S} / \mathrm{m}$ and exhibited good adsorption capacity for $\mathrm{CO}_{2}$ storage. Tang et al. ${ }^{97}$ used $\mathrm{Mg}$ vapor to reduce GO aerogels. The freeze-dried GO aerogel was heated in an ampoule with $\mathrm{Mg}$ powder at $700{ }^{\circ} \mathrm{C}$ for $5 \mathrm{~h}$. After magnesiothermic reaction, the reduced GO sheets were decorated with $\mathrm{MgO}$ nanocrystals, which were washed with acid and freeze-dried again. The final GA retained the original morphology with densities as low as $1.1 \mathrm{mg} / \mathrm{cm}^{3}$ and exhibited an electrical conductivity of $27 \mathrm{~S} / \mathrm{m}$. On compression, the sample had $<4 \%$ permanent deformation after 1000 cycles.

The other popular reduction method is thermal annealing. This is one of the most effective methods to achieve high electrical conductivity in the GA. Annealing at $800-1100{ }^{\circ} \mathrm{C}$ under inert gas produces aerogels with conductivities of $\sim 100 \mathrm{~S} / \mathrm{m} .{ }^{9,82}$ However, using an even higher thermal annealing temperature (1500-2500 ${ }^{\circ} \mathrm{C}$ ), the crystallinity of the graphene sheets is further increased, which is reflected in the Raman spectra, oxidative thermal stability, electrical conductivity, and mechanical properties ${ }^{98,99}$ (Fig. S9). For example, electrical conductivity can be enhancements of 5-6 times the values recorded at lower temperature anneals. This demonstrates the key role crystallinity plays in GA properties. Thermal reduction in a furnace is most common, but in some work, other means are used. For example, Hu et al. ${ }^{100}$ report synthesis of ultralight GAs 
via microwave irradiation. The aerogels show densities as low as $3 \mathrm{mg} / \mathrm{cm}^{3}$ and yet the structure fully recovers without fracture even after $90 \%$ compression.

\section{CNT/GAs}

In addition to CNT and GAs, there is also a considerable body of research devoted to composite CNT/GAs, which seek to create synergy by combining these two extraordinary carbon allotropes in the aerogel framework. ${ }^{23}$ Sun et al. ${ }^{101}$ reported synergistically assembled aerogels by combining CNTs and giant GO sheets to form hybrid aerogels. The aerogels were of extremely low-density (as low as $0.16 \mathrm{mg} / \mathrm{cm}^{3}$ ) and were prepared by freeze-drying solutions of CNT with GO sheets and subsequent reduction with hydrazine. The morphology of these aerogels was similar to that of GAs with an interconnected, porous 3D framework of randomly oriented sheets, except that entangled CNT networks covered the graphene sheets (Fig. S10). On detailed observation, multiple forms of CNT interconnections such as overlapping, twisting, and enwrapping with graphene were seen. The aerogels maintained mechanical integrity when compressed to $80 \%$ strain and fully recovered upon unloading. Compared with GAs of similar density, the CNT/GA hybrids also displayed good elasticity. The synergistic effect is attributed to strong interaction between graphene and CNTs, with CNTs reinforcing the graphene sheets like ribbing.

Zhang et al. ${ }^{102}$ synthesized CNT/GAs using the hydrothermal method. SWCNTs are first treated in acid to remove catalyst impurities before dispersing them with GO. Gelation is achieved in a Teflon-lined autoclave at $180{ }^{\circ} \mathrm{C}$ for $4 \mathrm{~h}$. The wet gel is then freeze-dried to yield the graphene/SWCNT aerogel. The surface area of this aerogel was reported to be $656 \mathrm{~m}^{2} / \mathrm{g}$, which is much higher than is typically reported for freeze-dried aerogels. It is presumed that the SWCNTs served as spacers between graphene sheets preventing restacking and thus allowing the final aerogel to retain more accessible surface area.

Researchers have also pursued green synthesis routes for fabrication of CNT/GAs. In the work by Sui et al., ${ }^{103}$ GO sheets and MWCNTs were sonicated together. Ascorbic acid was used as the chemical reducing agent to induce gelation and the wet gels were supercritically dried with $\mathrm{CO}_{2}$. The morphology of the aerogels had a 3D hierarchical pore structure with macropores in the micron regime and the solid walls of the aerogel were composed of CNTs and graphene sheets forming mesopores in the nanometer regime. These aerogels exhibited large surface areas and pore volumes, in addition to good electrical conductivity resulting in excellent sorbent performance for desalination, as well as oil and dye absorption.

A novel synthesis approach to CNT/GAs was reported by Kim et al. in which graphene was grown on CNT aerogels to make the composite. ${ }^{39} \mathrm{CNT}$ aerogels were coated with polyacrylonitrile (PAN), which was converted into multilayer graphene by means of a multistep pyrolysis process. The conversion of PAN to graphene was accomplished by first treating the aerogel at $210{ }^{\circ} \mathrm{C}$ in argon for $1.5 \mathrm{~h}$ to convert PAN to a condensed heterocyclic ring structure, then treating the aerogel at $1010{ }^{\circ} \mathrm{C}$ to convert the condensed heterocyclic structure to graphene. The volume fraction of graphene coating ranges from 0.0067 to 0.009 giving a porosity of $99 \%$ in the aerogels. The morphology of aerogels by TEM showed that $25-40 \%$ of the nanotubes are coated with 1-5 layers of graphene. The CNT/GAs completely recover their original shape with no mechanical failure after a compressive strain of $\geq 90 \%$ compared with permanent collapse of CNT aerogels under the same conditions (Fig. S11). The aerogels also exhibited excellent structural robustness. No significant plastic deformation or degradation in compressive strength was observed in these CNT/GAs after repeated loading and unloading for up to $10^{6}$ cycles at a strain of $60 \%$.

In addition to the previous example of growing graphene in a CNT aerogel, several researchers have reported growing CNTs in GAs to produce a CNT/GA. $\mathrm{Hu}$ et al. ${ }^{104}$ used a microwave irradiation-mediated approach for manufacturing of CNT/GAs, in which MWCNTs are vertically anchored on the surface of the graphene walls of the aerogels. This method starts with an ethylenediamine-functionalized GA that is exposed to microwave radiation to remove the functionalization and yield an ultralight GA (ULGA). The ULGA gel is impregnated with an acetone solution of ferrocene and then air-dried. Additional microwave irradiation leads to in situ super heating and growth of CNTs in the ULGA (Fig. S12). By varying the concentration of ferrocene solution from 5 to $20 \mathrm{mg} / \mathrm{mL}$, the authors increased the CNT loading from 14 to $46 \mathrm{wt} \%$. The CNT/GAs were superhydrophobic and highly compressible making them excellent recyclable oil sorbents. Lee et al. ${ }^{37}$ synthesized CNT/GA from a hydrothermally treated $\mathrm{NiCl}_{2}$-loaded GO suspension. The resultant wet gel was then freezedried to form graphene-metal salt aerogel that was now ready for CVD processing. Using a water-assisted thermal CVD process, CNTs were grown from the $\mathrm{Ni}$ nanoparticles (in situ reduced from Ni salt) embedded in the GA at $810{ }^{\circ} \mathrm{C}$ with acetylene as a carbon source. The morphology of the CNT/GAs revealed entangled CNTs covering the graphene sheets and bonded CNTs bridging the graphene layers. The CNT/GAs exhibited enhanced surface area, mechanical properties, and electrical properties compared with pure GAs. Wang et al. ${ }^{105}$ prepared similar CNT/GAs using Fe catalyst instead of $\mathrm{Ni}$ to grow the CNTs. These aerogels also showed enhanced properties and impressive sorption of various organics. 


\section{E. Diamond aerogels}

Diamond is a metastable allotrope of carbon well known for its extraordinary mechanical, thermal, and optical properties, as well as its chemical inertness. Realizing a high surface area aerogel consisting of nanodiamonds creates an exciting material with potential applications in a range of fields covering catalysis, photonics, sensing, and even drug delivery. ${ }^{106}$ Examples of diamond aerogels are still relatively limited, but two methods have been reported: (i) high pressure, high temperature (HPHT) conversion of an amorphous CA and (ii) the use of RF sol-gel chemistry to covalently cross-link nanodiamonds. Both methods are discussed below.

Pauzauskie et al. ${ }^{10}$ reported HPHT synthesis of diamond aerogels from an amorphous carbon precursor. In this study, the amorphous-to-crystalline phase transition is achieved by subjecting the amorphous precursor aerogel of density $0.04 \mathrm{~g} / \mathrm{cm}^{3}$ to a high pressure until the material reaches the diamond state in the carbon phase diagram and the material is further heated to temperatures slightly above $1580 \pm 40 \mathrm{~K}$ through a laser-heated diamond anvil cell (DAC) to overcome the kinetic barriers. The DAC with the amorphous aerogel is filled with supercritical neon at a pressure of $22 \mathrm{kpsi}$ (Fig. 6). To maintain the aerogel structure at all length scales, a near hydrostatic pressure is maintained inside the DAC cavity. Formation of diamond aerogel is confirmed from Raman spectra by tracking both $\mathrm{D}$ and $\mathrm{G}$ bands of the amorphous precursor at approximately $22.5 \mathrm{GPa}$. Comparing the Raman spectra before and after heating an additional peak is observed due to newly formed diamond. This is again confirmed through TEM, which reveals the highly porous aerogel morphology and crystalline diamond particles. Electron diffraction confirmed the conversion from amorphous carbon to cubic diamond (Fig. S13).

As the HPHT conversion process requires the use of a DAC, it can be cost prohibitive and the volume of diamond aerogel synthesis is limited to the size of the DAC. Therefore, Manandhar et al. ${ }^{106}$ proposed the use of RF sol-gel chemistry to create diamond aerogels on a much larger scale. Given the chemically inert surface of the nanodiamonds and the presence of some amorphous soot, the nanodiamonds were first treated at $450{ }^{\circ} \mathrm{C}$ for $8 \mathrm{~h}$ in air. This provides the oxygen surface functionality required for covalent bonding with the RF polymer. From here the strategy is similar to that used by Lim et al. for fast sol-gel synthesis of GAs. ${ }^{75}$ The nanodiamonds are suspended in acetonitrile, and gelation is achieved with the addition of RF and the acid catalyst. Final aerogels consist of nanodiamonds cross-linked with RF with surface areas greater than $500 \mathrm{~m}^{2} / \mathrm{g}$.

\section{F. Graphite aerogels}

Graphite is the most stable allotrope of carbon and consists of many stacked layers of graphene sheets.
Graphite is known for its excellent electrical and thermal conductivity, chemical and thermal stability, and low density. As such, in aerogel form, it is a potential candidate material for many of the same applications associated with CNT and GAs. Like diamond aerogels, examples of graphite aerogels are limited, but the reports below highlight the many benefits that such a material could provide.

Aerographite is the name by which most graphite aerogels are referred. The first example of this ultralightweight graphite aerogel was developed by a team of researchers from the University of Kiel and the Technical University of Hamburg. Mecklenburg et al. ${ }^{107}$ developed a single-step CVD synthesis method for the fabrication of aerographite from a freely adjustable $\mathrm{ZnO}$ network. The $\mathrm{ZnO}$ tetrapod templates (densities ranging from 0.15 to $0.8 \mathrm{~g} / \mathrm{cm})$ are placed in a two-zone $\left(200{ }^{\circ} \mathrm{C}\right.$ and $\left.760{ }^{\circ} \mathrm{C}\right)$ split tube furnace where the introduction of hydrogen gas flow reduces $\mathrm{ZnO}$ to metallic $\mathrm{Zn}$ that is precipitated into the exhaust system. The degree of crystalline order of the carbon structure and its morphology are controlled by the CVD parameters and also by the design of the $\mathrm{ZnO}$ templates (Fig. S14). During the synthesis, the carbonfeeding rate is a key parameter to adjust for the resulting density of aerographite (i.e., wall-thickness of graphitic layers of aerographite). Aerographite consists of a seamless interconnected network of closed shell microtubes, and the walls have nanoscopic thickness of $(\approx 15 \mathrm{~nm})$ like thin multiwall CNTs (MWCNTs) but have a microscale tube diameter (Fig. 7). Mechanical tests on the tetrapodlike aerographite exhibited an elastic recovery under compression for a $95 \%$ strain where the modulus of the sample (density $8.5 \mathrm{mg} / \mathrm{cm}^{3}$ ) increased to $160 \mathrm{kPa}$. The electrochemical performance of surface-modified aerographite tetrapodal network was measured though a three-electrode cell. Surface-functionalized aerographite with optimum porosity leads to significantly high specific capacitance $(640 \mathrm{~F} / \mathrm{g})$ with high energy $(14.2 \mathrm{~W} \mathrm{~h} / \mathrm{kg})$ and power densities $(9.67 \mathrm{~kW} / \mathrm{kg}) .{ }^{108}$ Besides the structural properties, aerographite samples exhibited piezoresistive behavior where the DC electrical conductivity can increase up $10 \mathrm{~S} / \mathrm{m}$ upon compression. ${ }^{109}$

Apart from using $\mathrm{ZnO}$ tetrapods, Hirahara et al. ${ }^{110}$ reported a new morphology of spiked-shell microparticles of aerographite where they used sea-urchin-like microparticles of $\mathrm{ZnO}$, the so-called $\mathrm{ZnO}$ nanorodmicrospheres as templates for the synthesis of these spiked-shell aerographite. Compressing these spiked shell aerographite, the authors reported an elastic recovery after $73 \%$ strain. Chandrasekaran et al. ${ }^{11}$ reported a thermoset composite with tetrapod-like aerographite as a filler in the range of $0.1-1.2 \mathrm{wt} \%$. The composites were electrically conductive $(2-8.7 \mathrm{~S} / \mathrm{m})$, and when uniaxially compressed, the composites exhibited an increase in energy absorption of $\sim 133 \%$ per unit volume 


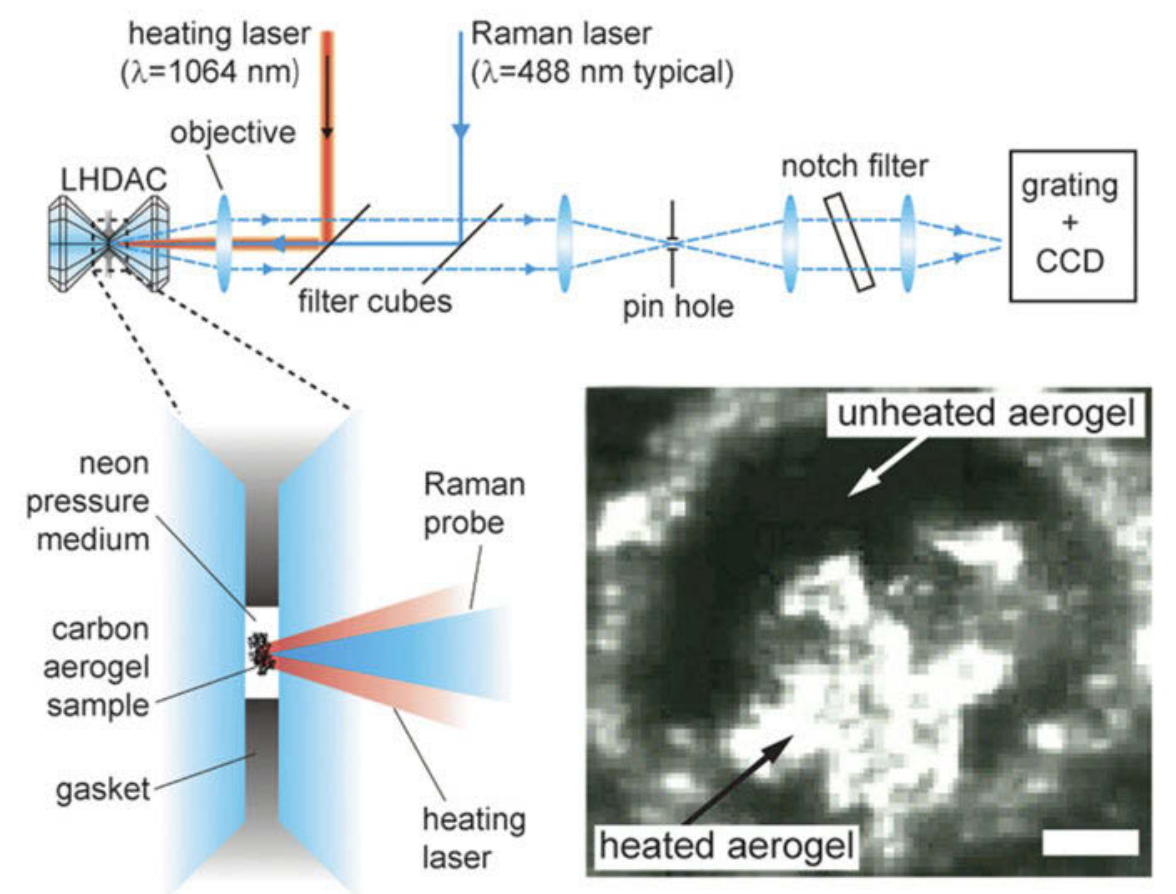

(a)

(b)
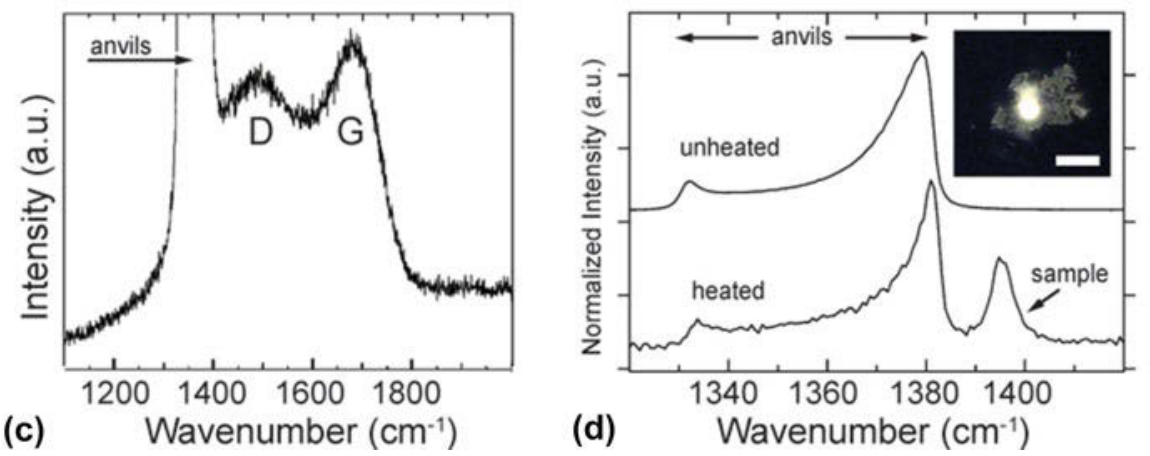

FIG. 6. Synthesis of diamond aerogel from amorphous CA precursor under high pressure and temperature. (a) Schematic of optical system used to heat the sample contained in the diamond anvil cell and to perform in situ Raman spectroscopy. The CA precursor is laser heated to likely more than $1600 \mathrm{~K}$ at several pressures between approximately 21 to $26 \mathrm{GPa}$ to drive the transition to diamond. Dashed lines show path followed by collected light. (b) Optical transmission micrograph of synthesized diamond aerogel above $20 \mathrm{GPa}$ following laser heating. Translucent regions were laser heated while dark regions were not heated as a control. Surrounding material is the rhenium metal gasket. Scale bar: $20 \mu \mathrm{m}$. (c) Raman spectrum of amorphous precursor at approximately $22.5 \mathrm{GPa}$ showing both D and G modes consistent with prior reports of amorphous carbon. The intense peak between 1300 and $1400 \mathrm{~cm}^{-1}$ is due to the diamond anvil or anvils. (d) Comparison of the Raman spectrum in (c) with that obtained after heating (note difference in $x$-axis scale from c). The additional peak is due to newly formed diamond. The peak is resolvable from that of the anvils because of the different stress states and the spatial selection of the instrument. The difference in signal-to-noise is partly attributed to intense fluorescence from the diamond aerogel. Inset: Optical micrograph of fluorescence from diamond aerogel. Scale bar: $50 \mu$ m. Reproduced by permission from Ref. 10 (Copyright (2011) National Academy of Science).

for $1.5 \mathrm{wt} \%$ of aerographite when compared with pure epoxy.

\section{GRAPHENE-INSPIRED AEROGELS}

The extraordinary properties and performance of graphene has inspired an explosion of research interest in a number of other $2 \mathrm{D}$ or layered materials. This interest in graphene-inspired materials has also become evident in the aerogel community. With the many successes reported in both the synthesis and application of GAs, researchers now look to create aerogel materials using other 2D materials, with the goal of realizing the novel properties and advantages that the aerogel form offers. Although inspired by graphene, synthesis of grapheneinspired aerogels tends to be more challenging because, typically, no water-soluble precursor (e.g., GO analog) is readily available. Therefore, in many cases, new 


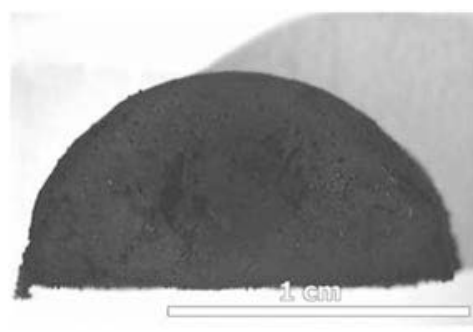

(a)

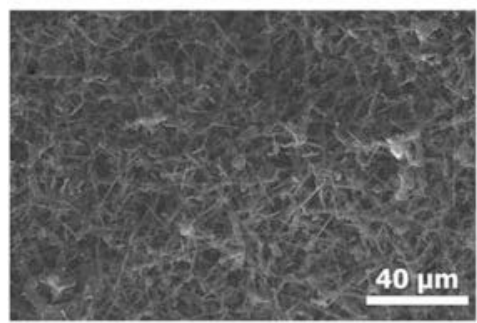

(b)

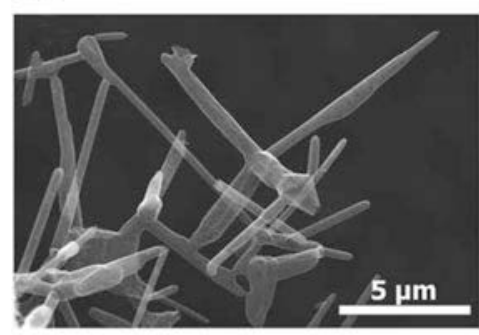

(c)

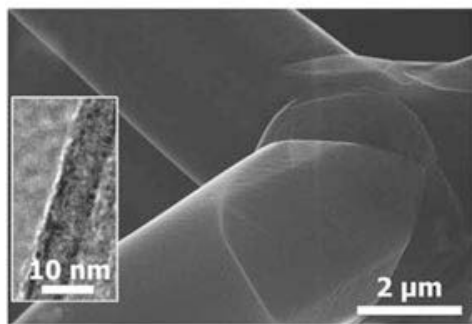

(d)

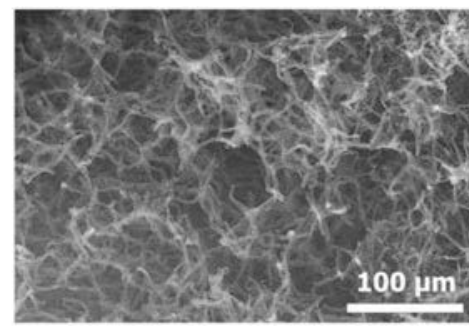

(e)

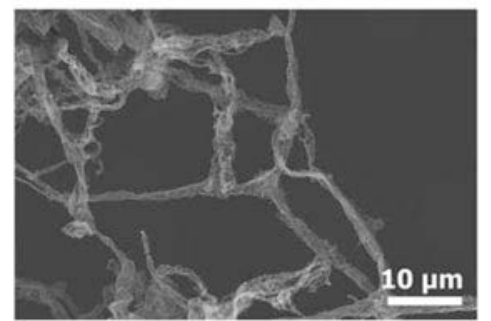

(f)

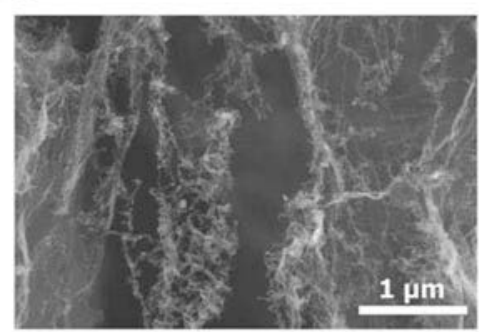

(g)

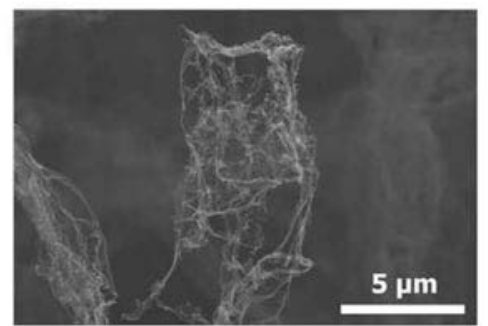

(h)

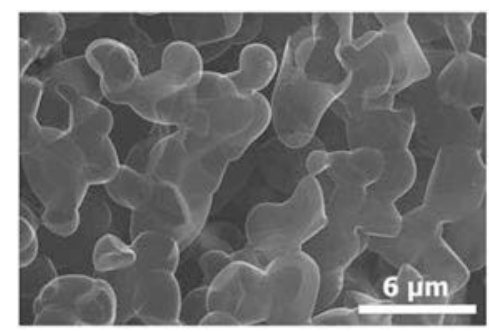

(i)

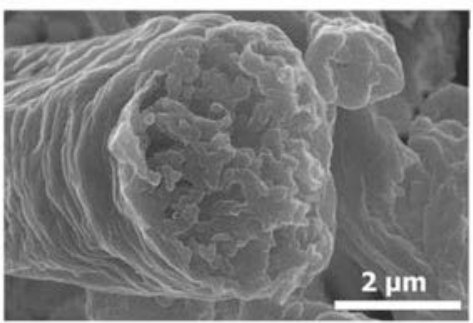

(j)

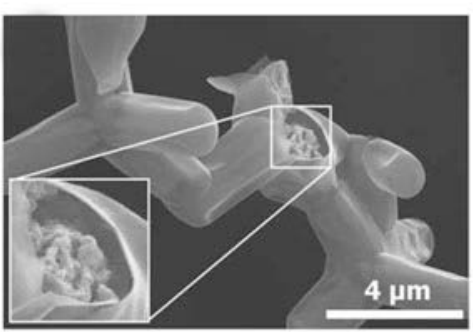

(k)

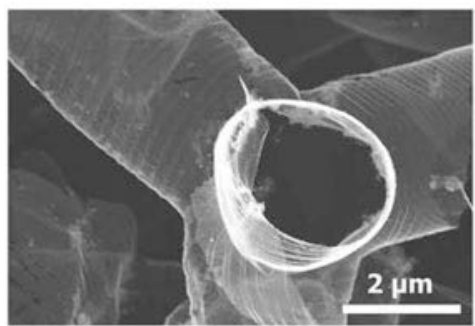

(I)

FIG. 7. Overview of different aerographite morphologies by controlled derivations of synthesis. (a) Photograph of macroscopic aerographite. (b-d) 3D interconnected structure of closed-shell graphitic aerographite in different magnifications and TEM inset of wall. (e-h) Hierarchical hollow framework configuration of aerographite in different magnifications. (i-l) Other variants of aerographite. (i) Aerographite network in low aspect bubble-like configuration. (j-k) Aerographite with nanoporous graphite filling. (l) Hollow corrugated pipe design of aerographite surface by detailed adoption of template shape. Reproduced by permission from Ref. 107 (Wiley and Sons).

strategies are adopted to realize these next-generation aerogel materials.

\section{A. Boron nitride aerogels}

Like graphene, hexagonal $\mathrm{BN}$ is a $2 \mathrm{D}$ material highly prized for its chemical inertness, high melting temperature, high thermal conductivity, and low density. However, in contrast to carbon, $\mathrm{BN}$ is an electrical insulator. It has a similar structure to graphene except that the carbon atoms are replaced by alternating boron and nitrogen atoms. The first example of a BN aerogel was reported by
Lindquist et al. ${ }^{112}$ in which a poly(borazinyl amine) aerogel is used as the precursor aerogel. This precursor aerogel is annealed up to $1200{ }^{\circ} \mathrm{C}$ in ammonia, and then up to $1500{ }^{\circ} \mathrm{C}$ in argon to produce turbostratic $\mathrm{BN}$ aerogels. These aerogels exhibited surface areas greater than $300 \mathrm{~m}^{2} / \mathrm{g}$, which were maintained at high temperatures and possessed very fine pore structure (mean pore diameters of 7-20 nm). However, the synthesis scheme for producing the poly(borazinyl amine) precursor gel requires an oxygen-free environment, which can be restrictive, therefore simpler synthetic routes have been 
pursued. For example, Rousseas et al. ${ }^{17}$ used a graphene precursor aerogel in a fairly straightforward $\mathrm{BN}$ aerogel synthesis scheme. This method takes advantage of one of the earliest known synthetic routes to pure BN. ${ }^{113}$ The reaction involves the carbothermal reduction of boron oxide in the presence of nitrogen according to the equation

$$
\mathrm{B}_{2} \mathrm{O}_{3}+3 \mathrm{C}+\mathrm{N}_{2} \rightarrow 2 \mathrm{BN}+3 \mathrm{CO}
$$

This method is widely used in industry ${ }^{114}$ and has been exploited to make other $\mathrm{BN}$ nanostructures from carbon precursors. ${ }^{115}$ Here, the GA serves as the carbon source for reduction of boron oxide and as the template for determining the pore structure of $\mathrm{BN}$ aerogel at temperatures above $1500{ }^{\circ} \mathrm{C}$. The effectiveness of this method is striking when looking at the aerogel before (black graphene precursor) and after (final white BN) as seen in Fig. 8. A closer look at the pore structure using TEM (Fig. S15) reveals that the $\mathrm{BN}$ aerogel is highly crystalline. In fact, it appears even more crystalline than the precursor GA. This is likely due to the fact that the GA itself becomes more crystalline at temperatures above $1500{ }^{\circ} \mathrm{C},{ }^{98}$ and this crystallinity is reproduced in the $\mathrm{BN}$ aerogel. The $\mathrm{BN}$ aerogel possesses surface areas greater than $400 \mathrm{~m}^{2} / \mathrm{g}$, excellent resistance to oxidation, and superhydrophobicity. These properties make it a promising material for reusable sorbent ${ }^{116}$ and combustible gas sensor ${ }^{117}$ technologies.

Lower temperature synthetic routes have also been reported for BN aerogels. Song et al. ${ }^{118}$ used a templateassisted method to grow $\mathrm{BN}$ aerogels at temperatures as low as $900{ }^{\circ} \mathrm{C}$. This method starts with a CA template and uses borazine as a source to deposit BN via CVD.

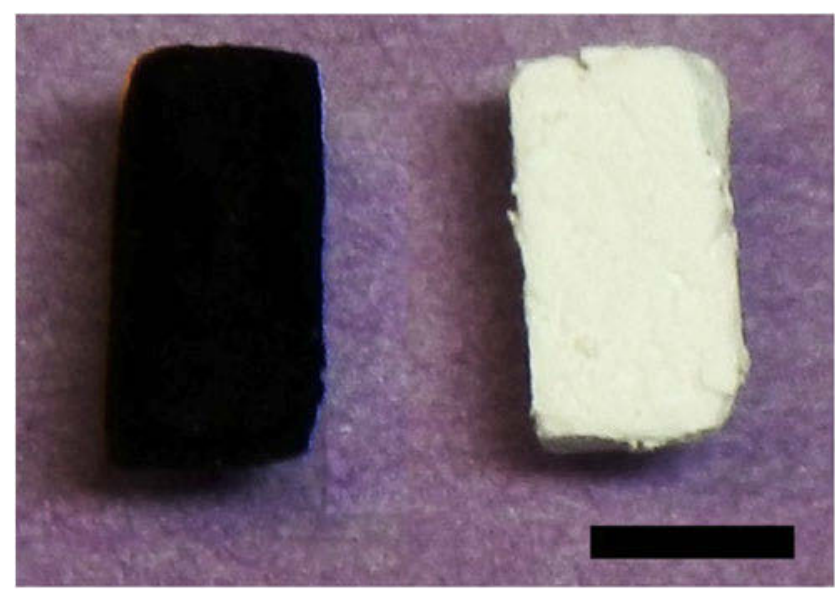

FIG. 8. Photograph of a precursor GA (left) and a converted BN aerogel (right). The color of the aerogel undergoes a significant color change, from pitch black to bright white, indicating a major change in the chemical composition. However, the overall macroscopic geometry of the samples remains unchanged. Samples shown have roughly square cross-sections. Scale bar is $5 \mathrm{~mm}$. Reproduced by permission from Ref. 17 (American Chemical Society).
The carbon template can be removed by calcination in oxygen at $600{ }^{\circ} \mathrm{C}$ to yield a BN aerogel with surface areas as high as $1051 \mathrm{~m}^{2} / \mathrm{g}$. A further reduction in the temperature required for $\mathrm{BN}$ aerogel synthesis was reported by Lei et al. ${ }^{119}$ Lei et al. succeeded in producing aqueous colloidal suspensions of $\mathrm{BN}$ which form hydrogels at room temperature. To achieve this, the $\mathrm{BN}$ powder is ball milled with urea to both exfoliate and functionalize the sheets with amine groups, which renders the BN water dispersible. Colloidal suspensions with concentrations as high as $30 \mathrm{mg} / \mathrm{mL}$ were prepared with this method. At these high concentrations, the suspensions form gels that can be freeze-dried to produce the aerogel. These aerogels have densities ranging from 1.4 to $20 \mathrm{mg} / \mathrm{cm}^{3}$ and surface areas greater than $250 \mathrm{~m}^{2} / \mathrm{g}$.

\section{B. Phosphorene aerogels}

Phosphorene, also referred to as BP, consists of a single layer of phosphorus atoms in a hexagonal lattice analogous to graphene. ${ }^{120,121}$ Like graphene, it has excellent transport properties and low density, but also has a widely tuneable band gap that depends on the number of layers present. $^{122}$ One of the more challenging aspects of working with BP is that it is not stable in air but will readily oxidize over time. The instability of BP in ambient conditions means that synthesizing a pure BP aerogel would be difficult. To overcome this obstacle, Xing et al. $^{123}$ sought to create a BP/GO composite aerogel. Given the instability of BP, an ultrafast GO gelation method was chosen that could produce a gel in a matter of minutes using poly(oxypropylene)diamine as the cross-linking agent. ${ }^{124}$ To prepare the composite gel, the poly(oxypropylene)diamine was added to an aqueous suspension of GO and BP nanoflakes (BPNFs), which were sealed in a vial and placed in a $90{ }^{\circ} \mathrm{C}$ bath for $1 \mathrm{~min}$. After the gel formed, it was freeze-dried to create the BP/ GO aerogel. The BP/GO aerogel exhibited sheet-like morphology expected of a 2D material and was of fairly low density (12 mg/cm ${ }^{3}$ with $\left.13.4 \mathrm{wt} \% \mathrm{BP}\right)$. Xing et al. found that BP was very stable in the composite aerogel, showing less oxidation than is found in bulk BP (Fig. S16) and that the BP remained stable for at least 30 days in air. It is suggested that the GO sheets cover and protect the BPNF within the aerogel. The BP/GO aerogel showed enhanced photothermal activity in comparison to the pristine GO aerogels owing to the presence of $\mathrm{BP}$ in the composite.

\section{Transition metal dichalcogenide aerogels}

Transition metal dichalcogenides (TMDs) are a class of layered material in which a single sheet consists of a layer of metal atoms (e.g., Mo, W, V, etc.) sandwiched between two layers of chalcogen atoms (e.g., S, Se, or Te). These 2D materials, like graphene, have generated 


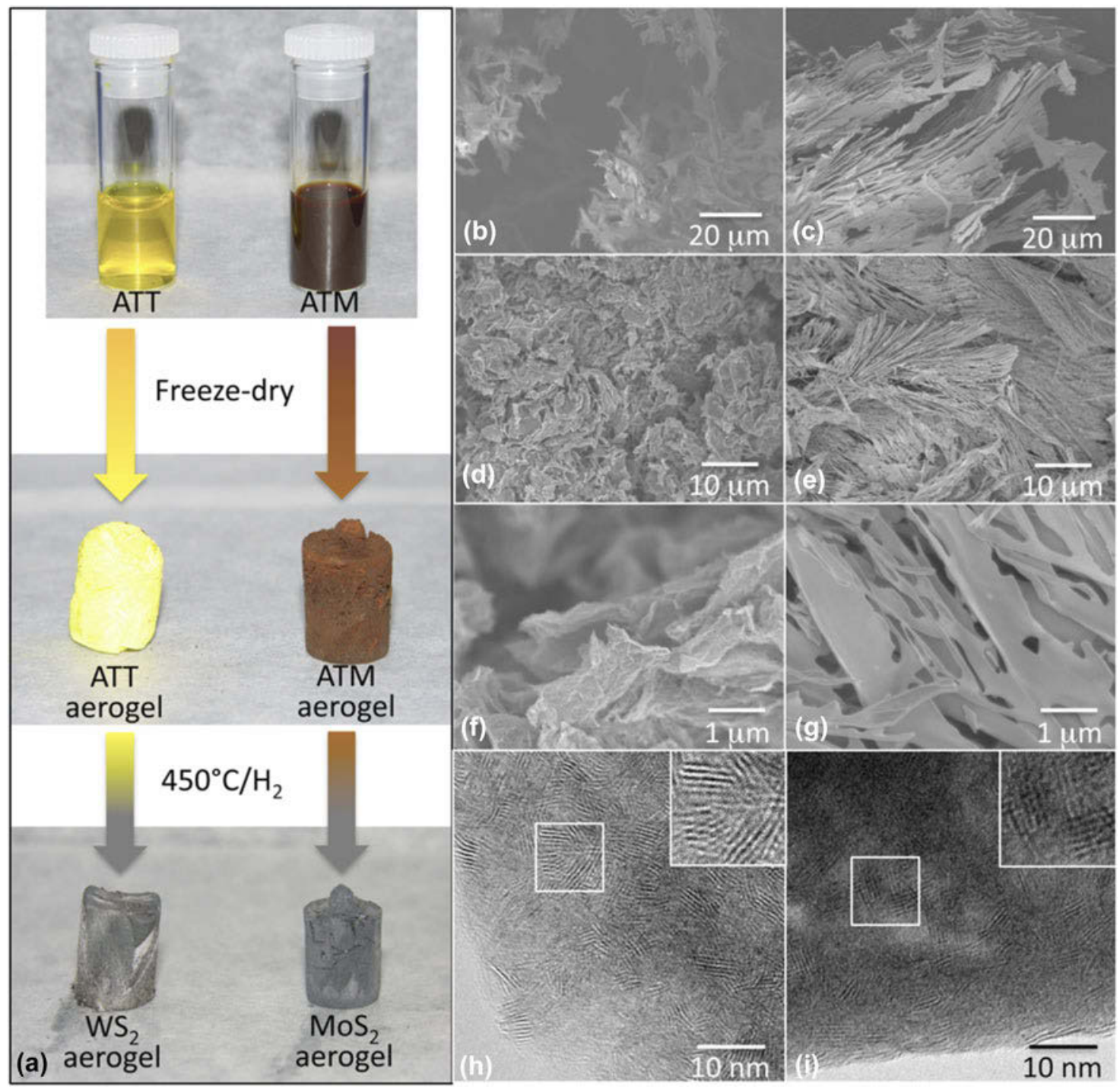

FIG. 9. (a) Synthesis scheme for $\mathrm{MoS}_{2}$ and $\mathrm{WS}_{2}$ aerogels. SEM images of (b) ATM, (c) ATT, (d and f) MoS 2 , and (e and g) WS 2 aerogels. TEM images of (h) $\mathrm{MoS}_{2}$ and (i) $\mathrm{WS}_{2}$ aerogels. The inset in images (h) and (i) is the magnification of the white box and is $10 \mathrm{~nm}$ in width. Reproduced by permission from Ref. 18 (American Chemical Society).

a lot of interest due to their exceptional properties for applications such as catalysis, energy storage, sensors, and electronics. ${ }^{125-127}$ Although there are a number of reports on chalcogels, ${ }^{128-132}$ examples of pure TMD aerogels remain limited. ${ }^{133}$ In 2015 , Worsley et al. ${ }^{18}$ reported a fairly straightforward method for $\mathrm{MoS}_{2}$ and $\mathrm{WS}_{2}$ aerogels. Aqueous solutions of precursor salts, ammonium thiomolybdate (ATM) and ammonium thiotungstate (ATT) were prepared and freeze-dried yielding a precursor aerogel. Next the precursor aerogels were simply annealed at $450{ }^{\circ} \mathrm{C}$ to yield pure TMD aerogels (Fig. 9). The $\mathrm{MoS}_{2}$ and $\mathrm{WS}_{2}$ aerogels exhibited the expected sheet-like morphology but due to significant restacking of the sheets during processing, surface areas were typically less than $20 \mathrm{~m}^{2} / \mathrm{g}$. Wu et al. ${ }^{134}$ reported a similar morphology by freeze casting an aqueous suspension of $\mathrm{WS}_{2}$ powder.

For energy storage and catalysis, typically larger surface areas are desired. In addition, for electrochemical storage or electrocatalysis a more conductive framework is preferred. Therefore, using the same general scheme, $\mathrm{MoS}_{2} / \mathrm{GAs}$ were synthesized. After the GA is immersed in the ATM solution, it is freeze-dried and annealed to produce the $\mathrm{MoS}_{2} / \mathrm{GA}$. This composite aerogel showed high surface areas (greater than $700 \mathrm{~m}^{2} / \mathrm{g}$ ), was electrically conductive, and showed good catalytic activity. ${ }^{18}$ The catalytic performance of $\mathrm{MoS}_{2} / \mathrm{GAs}$ is consistent with similar work by other groups. ${ }^{135,136} \mathrm{TMD} / \mathrm{GAs}$ have also shown promise in energy storage and sensor applications. $^{137-141}$ 


\section{3D PRINTING}

CAs have played an integral role in the development of 3D printed or additively manufactured aerogels. GAs, in particular, have led the way in terms of bringing these two fields. ${ }^{142} 3 \mathrm{D}$ printed aerogels are especially exciting because they represent the application of $3 \mathrm{D}$ printing to functional materials, not simply models. With the wide scope of applications already demonstrated for GAs, they are promising candidates for showing the potential of 3D printed functional materials. 3D printing is also capable of addressing one of the main weaknesses of aerogels, which is the inherently random nature of their pore morphology. This random pore morphology means that mass transport through an aerogel is typically slow and hard to tune. By using 3D printing to engineer the macropore architecture, mass transport can be easily tailored. Thus, applications that rely on the transport of some species through aerogels (e.g., energy storage, filtration, desalination, catalysis, etc.) can take advantage of optimally tailored pore morphology in 3D-printed aerogels to maximize their performance. ${ }^{143,144}$

To date, a number of different micro extrusion-based techniques have been reported to create 3D-printed CAs. In general, they all depend on flowing a carbon-based ink through a nozzle, which upon extrusion becomes a solid. Following is a summary of the methods currently reported for 3D printing CAs.

\section{A. Direct ink writing}

Zhu et al. ${ }^{145}$ developed a GO-based ink that made GAs compatible with the 3D-printing technique known as direct ink writing (DIW). DIW involves extruding the ink through a fine nozzle that is programmed to follow a toolpath which allows the construction of a 3D structure. A key requirement of the ink is that it is thixotropic, e.g., it flows under applied shear but reverts back to a self-supporting solid when the shear is removed. Here, the authors created inks consisting of high-concentration GO suspensions (20-40 mg/mL GO) that exhibited shear-thinning behavior as a non-Newtonian fluid. To further enhance the yield stress of the inks, viscosifiers such as hydrophilic fumed silica powders were added. These inks exhibit the desired viscoelasticity and have a long pot life (in weeks) when refrigerated. One of the challenges involved in 3D printing ultralow-density aerogels is that the ink must remain wet during printing and gelation. This is required so that the liquid from the wet gel can be either removed by freeze-drying or supercritical drying to avoid pore collapse due to capillary forces present during ambient drying. Hence, the ink was printed in an organic solvent bath (isooctane), which is not miscible with the aqueous GO ink. The organic solvent not only helps to keep the aerogel wet but also prevents drying of the ink in the nozzle which can cause clogging. After supercritically drying the printed gel, the structure was heated to $1050{ }^{\circ} \mathrm{C}$ under $\mathrm{N}_{2}$ to thermally reduce the GO to $s p^{2}$ carbon. Finally, the fumed silica was etched using hydrofluoric acid. The physical properties of the 3D printed aerogel are similar to those of the bulk aerogel (Fig. 10). The DIW aerogel had large surface areas (up to $1100 \mathrm{~m}^{2} / \mathrm{g}$ ) and pore volumes $\left(2-4 \mathrm{~cm}^{3} / \mathrm{g}\right.$ ), and a $\mathrm{C}: \mathrm{O}$ ratio above 20 . The electrical conductivity of the DIW aerogels varied from 87 to 278 $\mathrm{S} / \mathrm{m}$, and the aerogel exhibited supercompressibility up to 90\% compressive strain. The Young's modulus versus density of bulk and printed GAs obeyed the powerscaling law $\left(E \propto \rho^{2.5}\right)$ indicating that the failure mechanism is mainly bending dominated for these cellular materials. Interestingly, the engineered microlattice displayed a higher (almost twice) Young's modulus for a given density than bulk GAs. Electrical resistance change with cyclic compression up to $50 \%$ strain for 10 cycles for the printed GA was almost constant with a slight decrease of $<5 \%$ change. This is consistent with the results reported by Zhang et al. ${ }^{146}$ and Lin et al. ${ }^{144}$ showing that printed GAs are structurally resilient and highly conductive.

\section{B. Inkjet}

Zhang et al. ${ }^{146}$ combined 3D printing with freeze casting to fabricate GA with low density $\left(10 \mathrm{mg} / \mathrm{cm}^{3}\right)$. A low concentration aqueous GO suspension $(10 \mathrm{mg} / \mathrm{mL})$ was used as the ink. The ink was deposited by syringe directly on a cold sink which was maintained at a temperature of $-25{ }^{\circ} \mathrm{C}$. In this manner, individual layers of GO suspension were instantaneously frozen, constructing the 3D structure. Since the aqueous GO ink is rapidly frozen and ice crystals are selectively formed in the aqueous solutions, this technique can also be used to print material dropwise on demand onto the ice scaffold to obtain truly 3D structures. The low-viscosity inks exhibit Newtonian fluid behavior and the concentrations of the ink can go as low as $1 \mathrm{mg} / \mathrm{mL}$. The advantage of this printing technique is the interlayer diffusion in the printed structures. The liquid ink was dispensed on the frozen material which was maintained at $-25{ }^{\circ} \mathrm{C}$. Once in contact, this melted the frozen layer and the lowviscosity ink filled the voids between layers through surface tension and gravitational forces and both layers were re-frozen again as they were still in contact with the cold surface. Therefore, the 3D-printed structure exhibited good structural integrity from the bonding between layers (Fig. S17). The printed GAs possessed conductivities of $2-15 \mathrm{~S} / \mathrm{m}$ and were electrically resilient when compressed multiple times. The electromechanical properties were studied by monitoring the resistivity change as a function of compressive strain. The printed GAs displayed a linear behavior and no hysteresis. 


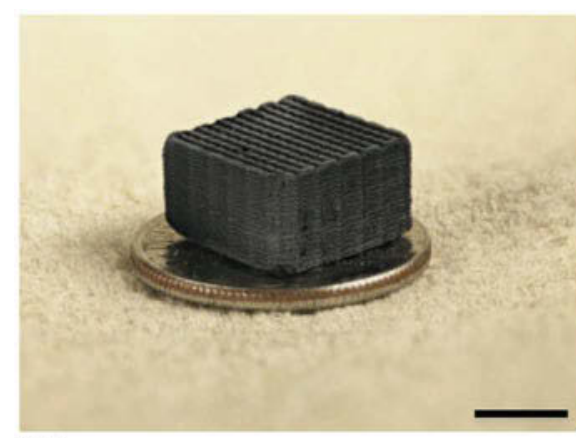

(a)

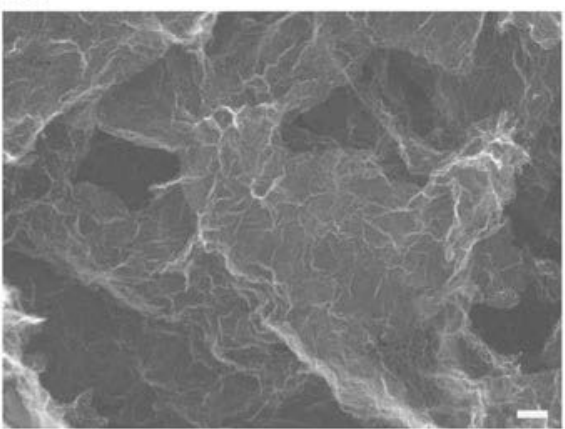

(c)

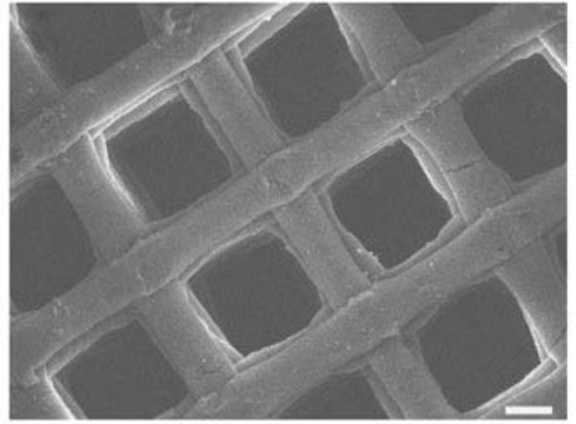

(b)

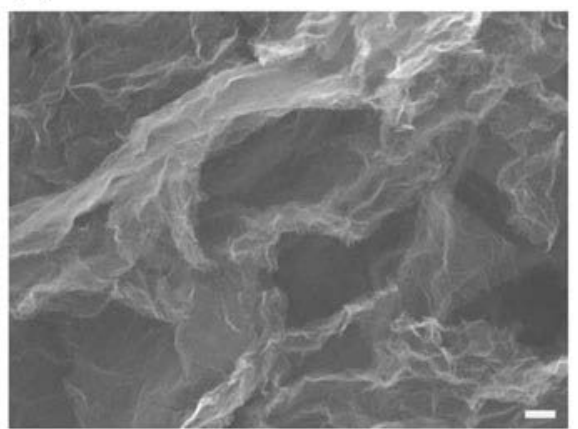

(d)

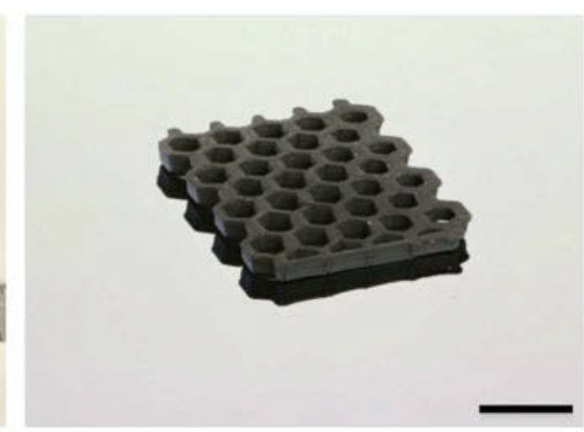

(f)

(e)

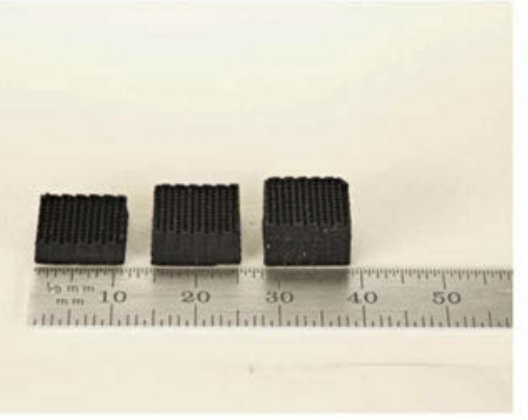

FIG. 10. Morphology and structure of GAs. (a) Optical image of a 3D printed GA microlattice. SEM images of (b) a 3D printed GA microlattice, (c) GA without RF after etching and (d) GA with $4 \mathrm{wt} \%$ RF after etching. Optical image of (e) 3D printed GA microlattices with varying thickness and (f) a 3D printed GA honeycomb. Scale bars, $5 \mathrm{~mm}$ (a), $200 \mathrm{~mm}$ (b), $100 \mathrm{~nm}$ (c, d), and $1 \mathrm{~cm}$ (f). Reproduced by permission from Ref. 145 (Nature Publishing Group).

Mechanical properties under compressive loading show a nonlinear superelastic behavior and a reversible compressibility up to $50 \%$ strain. 3D printed aerogels also exhibited remarkable viscoelastic stability over a temperature range from -100 to $300{ }^{\circ} \mathrm{C}$.

\section{Room temperature freeze gelation}

Lin et al. ${ }^{144}$ introduced the use of room temperature freeze gelation (RTFG) to 3D print pristine graphene, not GO. RTFG bears similarities with both the freeze casting used in the inkjet method ${ }^{146}$ and the DIW technique, ${ }^{145}$ Like DIW, RTFG extrudes a filament through a micronozzle and follows a toolpath to build the 3D structure. Temperature is used, similar to freeze casting, to make the ink self-supporting on deposition on the stage. Room temperature printing is possible because the ink consists of graphene suspended in an organic solvent (camphene or phenol) with a melting point above room temperature. Solvents with high vapor pressures were selected so that sublimation of the solvent could also proceed at room temperature. The resulting architectures are similar to those obtained via traditional DIW, while the solvent determines the microstructures. In fact, very different microstructures were obtained depending on the solvent used. With phenol, a lamellar, directionally biased morphology was produced, consistent with aqueous freeze casting reports. ${ }^{147,148}$ Camphene, however, solidifies more like a metal with "rough interfaces" which are templated into the GA, giving it a more random pore 


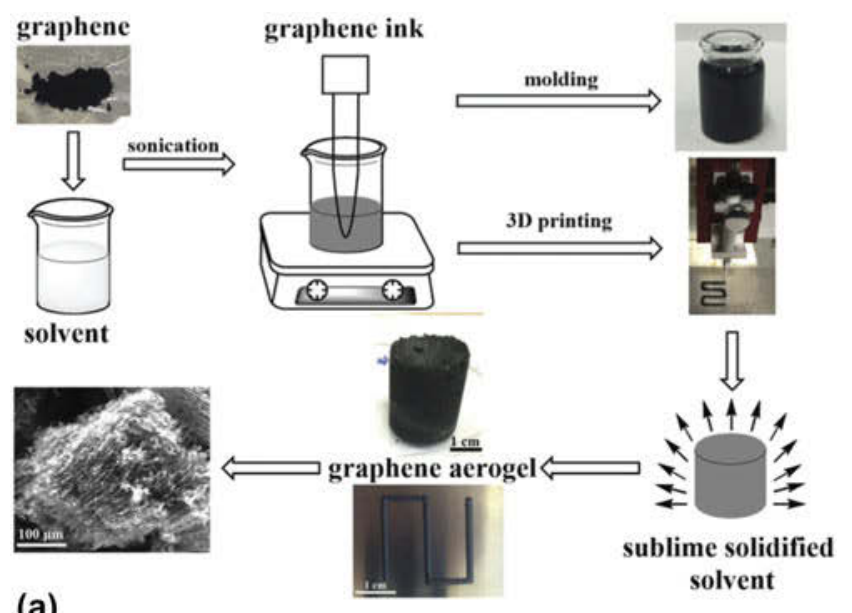

(a)

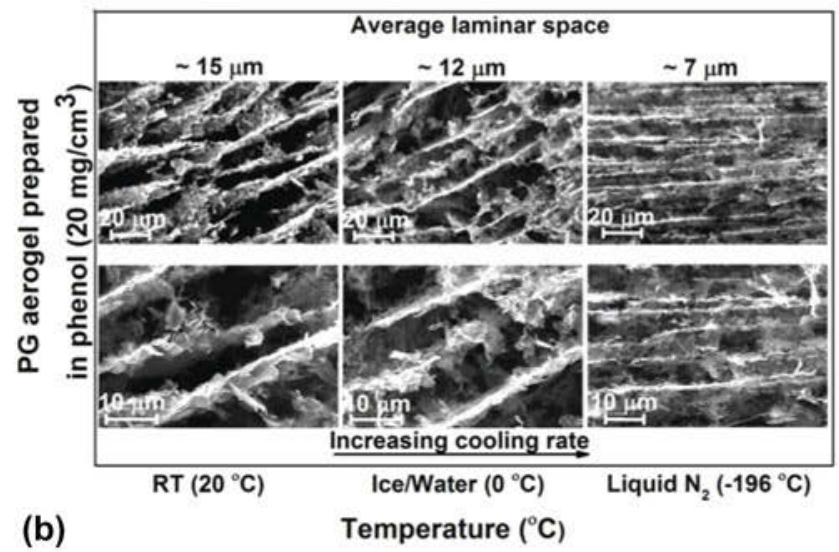

(b)

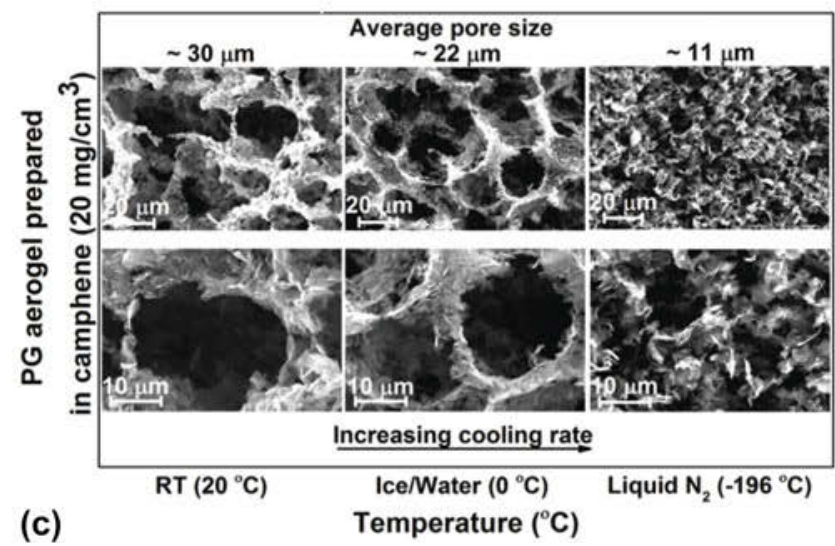

FIG. 11. (a) Schematic of the RTFG process. (b, c) SEM images of (b) phenol-based and (c) camphene-based aerogel structures cooled using liquid $\mathrm{N}_{2}$, an ice/water mixture, and at room temperature. Reproduced by permission from Ref. 144 (Wiley and Sons).

morphology (Fig. 11). The RTFG GAs did require polymer reinforcement to bolster mechanical properties due to an absence of chemical cross-links, but large surface areas (up to $700 \mathrm{~m}^{2} / \mathrm{g}$ ) and high electrical conductivities (up to $9 \mathrm{~S} / \mathrm{cm}$ ) were reported for densities of $20 \mathrm{mg} / \mathrm{cm}$ owing to the use of pristine graphene. The RTFG aerogels also showed promising performance as electrochemical double-layer capacitor electrodes with energy densities as high as $27 \mathrm{~W} \mathrm{~h} / \mathrm{kg}$ and power densities up to $21 \mathrm{~kW} / \mathrm{kg}$, some of the highest values reported for 3D printed aerogels.

\section{SUMMARY AND CONCLUSIONS}

Since their invention in the early 1990s CAs have continued to evolve and push the aerogel community forward. This evolution began with the synthesis of the various carbon allotropes (e.g., CNTs, diamond, graphite, and graphene), graphene-inspired aerogels (e.g., BN, phosphorene, and transition metal dichalcogenides) and continues as the leading edge in 3D-printed aerogel materials. The extraordinary and wide-ranging properties of these novel materials will continue to be a driver for next generation technologies in energy storage and conversion, filtration and separations, catalysis, and sensors.

3D printing of aerogels will also continue to be a growing field. With the potential to decouple traditionally correlated aerogel properties such as pore size and mass transport, research into adapting CAs to additional $3 \mathrm{D}$ printing methods as well as the use of modeling and optimization to determine the ideal aerogel architectures will continue to be areas of high interest. Lastly, in the wake of the advances in 3D-printed CAs, expanding 3D printing of other aerogel materials (e.g., metal oxides, metals, carbides, nitrides, etc.) is a clear area of future growth. With this in mind, the major role that CAs has played in the past 30 years should persist as the search for tomorrow's technology breakthroughs continues.

\section{ACKNOWLEDGMENTS}

This work was performed under the auspices of the U.S. Department of Energy by Lawrence Livermore National Laboratory under Contract DE-AC5207NA27344. Funding was provided by the Lawrence Livermore National Laboratory Directed Research and Development (LDRD) Grant Nos. 16-ERD-051, 14-SI-004, and 13-LW-099.

\section{REFERENCES}

1. S.S. Kistler, S. Swann, and E.G. Appel: Aerogel catalystsThoria preparation of catalyst and conversions of organic acids to ketones. Ind Eng Chem 26, 388 (1934).

2. S.S. Kistler and A.G. Caldwell: Thermal conductivity of silica aerogel. Ind Eng Chem 26, 658 (1934).

3. S.J. Teichner, G.A. Nicolaon, M.A. Vicarini, and G.E.E. Gardes: Inorganic oxide aerogels. Adv. Colloid Interface Sci. 5, 245 (1976).

4. P.H. Tewari, A.J. Hunt, and K.D. Lofftus: Ambient-temperature supercritical drying of transparent silica aerogels. Mater. Lett. 3, 363 (1985).

5. A.E. Gash, T.M. Tillotson, J.H. Satcher, J.F. Poco, L.W. Hrubesh, and R.L. Simpson: Use of epoxides in the sol-gel 
synthesis of porous iron(III) oxide monoliths from Fe(III) salts. Chem. Mater. 13, 999 (2001).

6. R.W. Pekala: Organic aerogels from the polycondensation of resorcinol with formaldehyde. J. Mater. Sci. 24, 3221 (1989).

7. A.W.P. Fung, Z.H. Wang, K. Lu, M.S. Dresselhaus, and R.W. Pekala: Characterization of carbon aerogels by transport measurements. J. Mater. Res. 8, 1875 (1993).

8. M.B. Bryning, D.E. Milkie, M.F. Islam, L.A. Hough, J.M. Kikkawa, and A.G. Yodh: Carbon nanotube aerogels. Adv. Mater. 19, 661 (2007).

9. M.A. Worsley, P.J. Pauzauskie, T.Y. Olson, J. Biener, J.H. Satcher, and T.F. Baumann: Synthesis of graphene aerogel with high electrical conductivity. J. Am. Chem. Soc. 132, 14067 (2010).

10. P.J. Pauzauskie, J.C. Crowhurst, M.A. Worsley, T.A. Laurence, A.L.D. Kilcoyne, Y.M. Wang, T.M. Willey, K.S. Visbeck, S.C. Fakra, W.J. Evans, J.M. Zaug, and J.H. Satcher: Synthesis and characterization of a nanocrystalline diamond aerogel. Proc. Natl. Acad. Sci. U. S. A. 108, 8550 (2011).

11. D.R. Rolison and B. Dunn: Electrically conductive oxide aerogels: New materials in electrochemistry. J. Mater. Chem. 11, 963 (2001)

12. J.L. Mohanan, I.U. Arachchige, and S.L. Brock: Porous semiconductor chalcogenide aerogels. Science 307, 397 (2005).

13. B.C. Tappan, M.H. Huynh, M.A. Hiskey, D.E. Chavez, E.P. Luther, J.T. Mang, and S.F. Son: Ultralow-density nanostructured metal foams: Combustion synthesis, morphology, and composition. J. Am. Chem. Soc. 128, 6589 (2006).

14. G.W. Nyce, J.R. Hayes, A.V. Hamza, and J.H. Satcher: Synthesis and characterization of hierarchical porous gold materials. Chem. Mater. 19, 344 (2007).

15. N. Leventis, N. Chandrasekaran, C. Sotiriou-Leventis, and A. Mumtaz: Smelting in the age of nano: Iron aerogels. J. Mater. Chem. 19, 63 (2009).

16. S.M. Jung, H.Y. Jung, M.S. Dresselhaus, Y.J. Jung, and J. Kong: A facile route for 3D aerogels from nanostructured 1D and 2D materials. Sci. Rep. 2, 849 (2012).

17. M. Rousseas, A.P. Goldstein, W. Mickelson, M.A. Worsley, L. Woo, and A. Zettl: Synthesis of highly crystalline $s p^{2}$-bonded boron nitride aerogels. ACS Nano 7, 8540 (2013).

18. M.A. Worsley, S.J. Shin, M.D. Merrill, J. Lenhardt, A.J. Nelson, L.Y. Woo, A.E. Gash, T.F. Baumann, and C.A. Orme: Ultra low density, monolithic $\mathrm{WS}_{2}, \mathrm{MoS}_{2}$, and $\mathrm{MoS}_{2}$ /graphene aerogels. ACS Nano 9, 4698 (2015).

19. S. Iijima and T. Ichihashi: Single-shell carbon nanotubes of 1-nm diameter. Nature 363, 603 (1993).

20. H.W. Kroto, J.R. Heath, S.C. Obrien, R.F. Curl, and R.E. Smalley: C-60-buckminsterfullerene. Nature 318, 162 (1985).

21. K.S. Novoselov, A.K. Geim, S.V. Morozov, D. Jiang, Y. Zhang, S.V. Dubonos, I.V. Grigorieva, and A.A. Firsov: Electric field effect in atomically thin carbon films. Science 306, 666 (2004).

22. S.A. Al-Muhtaseb and J.A. Ritter: Preparation and properties of resorcinol-formaldehyde organic and carbon gels. Adv. Mater. 15, 101 (2003).

23. S. Nardecchia, D. Carriazo, M.L. Ferrer, M.C. Gutierrez, and F. del Monte: Three dimensional macroporous architectures and aerogels built of carbon nanotubes and/or graphene: Synthesis and applications. Chem. Soc. Rev. 42, 794 (2013).

24. M. Antonietti, N. Fechler, and T-P. Fellinger: Carbon aerogels and monoliths: Control of porosity and nanoarchitecture via sol-gel routes. Chem. Mater. 26, 196 (2014).

25. A. Allahbakhsh and A.R. Bahramian: Self-assembled and pyrolyzed carbon aerogels: An overview of their preparation mechanisms, properties and applications. Nanoscale 7, 14139 (2015).

26. G. George and G. Costas: Graphene aerogels: A review. $2 D$ Mater. 4, 032001 (2017).

27. A.A. Balandin: Thermal properties of graphene and nanostructured carbon materials. Nat. Mater. 10, 569 (2011).

28. C.M. Leroy, F. Carn, R. Backov, M. Trinquecoste, and P. Delhaes: Multiwalled-carbon-nanotube-based carbon foams. Carbon 45, 2317 (2007).

29. M.A. Worsley, S.O. Kucheyev, J.D. Kuntz, A.V. Hamza, J.H. Satcher, and T.F. Baumann: Stiff and electrically conductive composites of carbon nanotube aerogels and polymers. J. Mater. Chem. 19, 3370 (2009).

30. M.A. Worsley, S.O. Kucheyev, J.D. Kuntz, T.Y. Olson, T.Y.J. Han, A.V. Hamza, J.H. Satcher, and T.F. Baumann: Carbon scaffolds for stiff and highly conductive monolithic oxide-carbon nanotube composites. Chem. Mater. 23, 3054 (2011).

31. D.N. Futaba, K. Hata, T. Yamada, T. Hiraoka, Y. Hayamizu, Y. Kakudate, O. Tanaike, H. Hatori, M. Yumura, and S. Iijima: Shape-engineerable and highly densely packed single-walled carbon nanotubes and their application as super-capacitor electrodes. Nat. Mater. 5, 987 (2006).

32. J.K. Holt, H.G. Park, Y.M. Wang, M. Stadermann, A.B. Artyukhin, C.P. Grigoropoulos, A. Noy, and O. Bakajin: Fast mass transport through sub-2-nanometer carbon nanotubes. Science 312, 1034 (2006).

33. K.H. Kim, M. Vural, and M.F. Islam: Single-walled carbon nanotube aerogel-based elastic conductors. Adv. Mater. 23, 2865 (2011).

34. L. Wang, M. Wang, Z-H. Huang, T. Cui, X. Gui, F. Kang, $\mathrm{K}$. Wang, and $\mathrm{D}$. Wu: Capacitive deionization of $\mathrm{NaCl}$ solutions using carbon nanotube sponge electrodes. J. Mater. Chem. 21, 18295 (2011).

35. X. Gui, J. Wei, K. Wang, A. Cao, H. Zhu, Y. Jia, Q. Shu, and D. Wu: Carbon nanotube sponges. Adv. Mater. 22, 617 (2010).

36. M.A. Worsley, M. Stadermann, Y.M.M. Wang, J.H. Satcher, and T.F. Baumann: High surface area carbon aerogels as porous substrates for direct growth of carbon nanotubes. Chem. Commun. 46, 9253 (2010).

37. B. Lee, S. Lee, M. Lee, D.H. Jeong, Y. Baek, J. Yoon, and Y.H. Kim: Carbon nanotube-bonded graphene hybrid aerogels and their application to water purification. Nanoscale 7, 6782 (2015).

38. C. Hoecker, F. Smail, M. Pick, and A. Boies: The influence of carbon source and catalyst nanoparticles on CVD synthesis of CNT aerogel. Chem. Eng. J. 314, 388 (2017).

39. K.H. Kim, Y. Oh, and M.F. Islam: Graphene coating makes carbon nanotube aerogels superelastic and resistant to fatigue. Nat. Nanotechnol. 7, 562 (2012).

40. Z. Lin, X. Gui, Q. Gan, W. Chen, X. Cheng, M. Liu, Y. Zhu, Y. Yang, A. Cao, and Z. Tang: In situ welding carbon nanotubes into a porous solid with super-high compressive strength and fatigue resistance. Sci. Rep. 5, 11336 (2015).

41. M.A. Worsley, J.H. Satcher, and T.F. Baumann: Synthesis and characterization of monolithic carbon aerogel nanocomposites containing double-walled carbon nanotubes. Langmuir 24, 9763 (2008).

42. M.A. Worsley, S.O. Kucheyev, J.H. Satcher, Jr., A.V. Hamza, and T.F. Baumann: Mechanically robust and electrically conductive carbon nanotube foams. Appl. Phys. Lett. 94, 073115 (2009)

43. R.W. Pekala, C.T. Alviso, and J.D. Lemay: Organic aerogelsMicrostructural dependence of mechanical-properties in compression. J. Non-Cryst. Solids 125, 67 (1990).

44. T. Woignier, J. Reynes, A.H. Alaoui, I. Beurroies, and J. Phalippou: Different kinds of structure in aerogels: Relation- 
ships with the mechanical properties. J. Non-Cryst. Solids 241, 45 (1998).

45. N. Leventis, C. Sotiriou-Leventis, G. Zhang, and A-M.M. Rawashdeh: Nanoengineering strong silica aerogels. Nano Lett. 2, 957 (2002).

46. S.O. Kucheyev, T.F. Baumann, C.A. Cox, Y.M. Wang, J.H. Satcher, A.V. Hamza, and J.E. Bradby: Nanoengineering mechanically robust aerogels via control of foam morphology. Appl. Phys. Lett. 89 (2006).

47. M.C. Gutiérrez, D. Carriazo, A. Tamayo, R. Jiménez, F. Picó, J.M. Rojo, M.L. Ferrer, and F. del Monte: Deep-eutectic-solventassisted synthesis of hierarchical carbon electrodes exhibiting capacitance retention at high current densities. Chem.-Eur. J. 17, 10533 (2011).

48. M.A. Worsley, P.J. Pauzauskie, S.O. Kucheyev, J.M. Zaug, A.V. Hamza, J.H. Satcher, Jr., and T.F. Baumann: Properties of single-walled carbon nanotube-based aerogels as a function of nanotube loading. Acta Mater. 57, 5131 (2009).

49. M. De Marco, F. Markoulidis, R. Menzel, S.M. Bawaked, M. Mokhtar, S.A. Al-Thabaiti, S.N. Basahel, and M.S.P. Shaffer: Cross-linked single-walled carbon nanotube aerogel electrodes via reductive coupling chemistry. J. Mater. Chem. A 4, 5385 (2016).

50. R.R. Kohlmeyer, M. Lor, J. Deng, H. Liu, and J. Chen: Preparation of stable carbon nanotube aerogels with high electrical conductivity and porosity. Carbon 49, 2352 (2011).

51. J. Zou, J. Liu, A.S. Karakoti, A. Kumar, D. Joung, Q. Li, S.I. Khondaker, S. Seal, and L. Zhai: Ultralight multiwalled carbon nanotube aerogel. ACS Nano 4, 7293 (2010).

52. M.C. Gutiérrez, M.J. Hortigüela, J.M. Amarilla, R. Jiménez, M.L. Ferrer, and F. del Monte: Macroporous 3D architectures of self-assembled MWCNT surface decorated with Pt nanoparticles as anodes for a direct methanol fuel cell. J. Phys. Chem. C 111, 5557 (2007).

53. S-M. Kwon, H-S. Kim, and H-J. Jin: Multiwalled carbon nanotube cryogels with aligned and non-aligned porous structures. Polymer 50, 2786 (2009).

54. G.N. Ostojic: Optical properties of assembled single-walled carbon nanotube gels. ChemPhysChem 13, 2102 (2012).

55. X.L. Li, G.Y. Zhang, X.D. Bai, X.M. Sun, X.R. Wang, E. Wang, and H.J. Dai: Highly conducting graphene sheets and LangmuirBlodgett films. Nat. Nanotechnol. 3, 538 (2008).

56. A.K. Geim and K.S. Novoselov: The rise of graphene. Nat. Mater. 6, 183 (2007).

57. A. Peigney, C. Laurent, E. Flahaut, R.R. Bacsa, and A. Rousset: Specific surface area of carbon nanotubes and bundles of carbon nanotubes. Carbon 39, 507 (2001).

58. C. Lee, X. Wei, J.W. Kysar, and J. Hone: Measurement of the elastic properties and intrinsic strength of monolayer graphene. Science 321, 385 (2008).

59. M. Pumera: Graphene-based nanomaterials for energy storage. Energy Environ. Sci. 4, 668 (2011).

60. Y.W. Zhu, S. Murali, M.D. Stoller, K.J. Ganesh, W.W. Cai, P.J. Ferreira, A. Pirkle, R.M. Wallace, K.A. Cychosz, M. Thommes, D. Su, E.A. Stach, and R.S. Ruoff: Carbon-based supercapacitors produced by activation of graphene. Science $\mathbf{3 3 2}$, 1537 (2011).

61. F.N. Xia, D.B. Farmer, Y.M. Lin, and P. Avouris: Graphene fieldeffect transistors with high on/off current ratio and large transport band gap at room temperature. Nano Lett. 10, 715 (2010).

62. F. Schwierz: Graphene transistors. Nat. Nanotechnol. 5, 487 (2010).

63. L.S. Zhang, L.Y. Jiang, H.J. Yan, W.D. Wang, W. Wang, W.G. Song, Y.G. Guo, and L.J. Wan: Mono dispersed $\mathrm{SnO}_{2}$ nanoparticles on both sides of single layer graphene sheets as anode materials in Li-ion batteries. J. Mater. Chem. 20, 5462 (2010).

64. L-H. Shao, J. Biener, H-J. Jin, M.M. Biener, T.F. Baumann, and J. Weissmüller: Electrically tunable nanoporous carbon hybrid actuators. Adv. Funct. Mater. 22, 3029-3034 (2012).

65. F. Schedin, A.K. Geim, S.V. Morozov, E.W. Hill, P. Blake, M.I. Katsnelson, and K.S. Novoselov: Detection of individual gas molecules adsorbed on graphene. Nat. Mater. 6, 652 (2007).

66. H. Bai, C. Li, X.L. Wang, and G.Q. Shi: A pH-sensitive graphene oxide composite hydrogel. Chem. Commun. 46, 2376 (2010).

67. B.C. Brodie: On the atomic weight of graphite. Philos. Trans. $R$. Soc. London 149, 249 (1859).

68. W.S. Hummers, Jr. and R.E. Offeman: Preparation of graphitic oxide. J. Am. Chem. Soc. 80, 1339 (1958).

69. H. Bi, I.W. Chen, T. Lin, and F. Huang: A new tubular graphene form of a tetrahedrally connected cellular structure. Adv. Mater. 27, 5943 (2015).

70. Y.X. Xu, K.X. Sheng, C. Li, and G.Q. Shi: Self-assembled graphene hydrogel via a one-step hydrothermal process. ACS Nano 4, 4324 (2010).

71. C-C. Ji, M-W. Xu, S-J. Bao, C-J. Cai, Z-J. Lu, H. Chai, F. Yang, and H. Wei: Self-assembly of three-dimensional interconnected graphene-based aerogels and its application in supercapacitors. J. Colloid Interface Sci. 407, 416 (2013).

72. A.P. Goldstein, W. Mickelson, A. Machness, G. Lee, M.A. Worsley, L. Woo, and A. Zettl: Simultaneous sheet cross-linking and deoxygenation in the graphene oxide sol-gel transition. J. Phys. Chem. C 118, 28855 (2014).

73. P. Zang, S. Gao, L. Dang, Z. Liu, and Z. Lei: Green synthesis of holey graphene sheets and their assembly into aerogel with improved ion transport property. Electrochim. Acta 212, 171 (2016).

74. M.A. Worsley, T.Y. Olson, J.R. Lee, T.M. Willey, M.H. Nielsen, S.K. Roberts, P.J. Pauzauskie, J. Biener, J.H. Satcher, Jr., and T.F. Baumann: High surface area, $s p^{2}$-cross-linked threedimensional graphene monoliths. J. Phys. Chem. Lett. 2, 921 (2011).

75. M.B. Lim, M. Hu, S. Manandhar, A. Sakshaug, A. Strong, L. Riley, and P.J. Pauzauskie: Ultrafast sol-gel synthesis of graphene aerogel materials. Carbon 95, 616 (2015).

76. S. Mulik, C. Sotiriou-Leventis, and N. Leventis: Time-efficient acid-catalyzed synthesis of resorcinol-formaldehyde aerogels. Chem. Mater. 19, 6138 (2007).

77. Z.H. Tang, S.L. Shen, J. Zhuang, and X. Wang: Noble-metalpromoted three-dimensional macroassembly of single-layered graphene oxide. Angew. Chem., Int. Ed. 49, 4603 (2010).

78. Y. Xu, Q. Wu, Y. Sun, H. Bai, and G. Shi: Three-dimensional self-assembly of graphene oxide and DNA into multifunctional hydrogels. ACS Nano 4, 7358 (2010).

79. Y-C. Shi, A-J. Wang, X-L. Wu, J-R. Chen, and J-J. Feng: Greenassembly of three-dimensional porous graphene hydrogels for efficient removal of organic dyes. J. Colloid Interface Sci. 484, 254 (2016).

80. H. Bai, C. Li, X. Wang, and G. Shi: On the gelation of graphene oxide. J. Phys. Chem. C 115, 5545 (2011).

81. M.A. Worsley, S. Charnvanichborikarn, E. Montalvo, S.J. Shin, E.D. Tylski, J.P. Lewicki, A.J. Nelson, J.H. Satcher, J. Biener, T.F. Baumann, and S.O. Kucheyev: Toward macroscale, isotropic carbons with graphene-sheet-like electrical and mechanical properties. Adv. Funct. Mater., 24, 4259 (2014).

82. M.A. Worsley, S.O. Kucheyev, H.E. Mason, M.D. Merrill, B.P. Mayer, J. Lewicki, C.A. Valdez, M.E. Suss, M. Stadermann, P.J. Pauzauskie, J.H. Satcher, J. Biener, and 
T.F. Baumann: Mechanically robust 3D graphene macroassembly with high surface area. Chem. Commun. 48, 8428 (2012).

83. W. Chen and L. Yan: In situ self-assembly of mild chemical reduction graphene for three-dimensional architectures. Nanoscale 3, 3132 (2011).

84. W. Wan, F. Zhang, S. Yu, R. Zhang, and Y. Zhou: Hydrothermal formation of graphene aerogel for oil sorption: The role of reducing agent, reaction time and temperature. New J. Chem. 40, 3040 (2016).

85. X. Zhang, Z. Sui, B. Xu, S. Yue, Y. Luo, W. Zhan, and B. Liu: Mechanically strong and highly conductive graphene aerogel and its use as electrodes for electrochemical power sources. J. Mater. Chem. 21, 6494 (2011).

86. Z. Fan, D.Z.Y. Tng, S.T. Nguyen, J. Feng, C. Lin, P. Xiao, L. Lu, and H.M. Duong: Morphology effects on electrical and thermal properties of binderless graphene aerogels. Chem. Phys. Lett. 561, 92 (2013).

87. Y. Xie, Z. Meng, T. Cai, and W-Q. Han: Effect of boron-doping on the graphene aerogel used as cathode for the lithium-sulfur battery. ACS Appl. Mater. Interfaces 7, 25202 (2015).

88. Z. Chen, H. Li, R. Tian, H. Duan, Y. Guo, Y. Chen, J. Zhou, C. Zhang, R. Dugnani, and H. Liu: Three dimensional graphene aerogels as binder-less, freestanding, elastic and highperformance electrodes for lithium-ion batteries. Sci. Rep. 6, 27365 (2016).

89. X. Zhang, D. Liu, L. Yang, L. Zhou, and T. You: Self-assembled three-dimensional graphene-based materials for dye adsorption and catalysis. J. Mater. Chem. A 3, 10031 (2015).

90. Y. Qiao, G-Y. Wen, X-S. Wu, and L. Zou: 1-Cysteine tailored porous graphene aerogel for enhanced power generation in microbial fuel cells. RSC Adv. 5, 58921 (2015).

91. J. Luo, J. Lai, N. Zhang, Y. Liu, R. Liu, and X. Liu: Tannic acid induced self-assembly of three-dimensional graphene with good adsorption and antibacterial properties. ACS Sustainable Chem. Eng. 4, 1404 (2016).

92. B. Zhang, J. Zhang, X. Sang, C. Liu, T. Luo, L. Peng, B. Han, X. Tan, X. Ma, D. Wang, and N. Zhao: Cellular graphene aerogel combines ultralow weight and high mechanical strength: A highly efficient reactor for catalytic hydrogenation. Sci. Rep. 6 , 25830 (2016)

93. Y. He, F. Wu, X. Sun, R. Li, Y. Guo, C. Li, L. Zhang, F. Xing, W. Wang, and J. Gao: Factors that affect pickering emulsions stabilized by graphene oxide. ACS Appl. Mater. Interfaces $\mathbf{5}$, 4843 (2013).

94. Y. He, J. Li, L. Li, and J. Li: Gamma-ray irradiation-induced reduction and self-assembly of graphene oxide into threedimensional graphene aerogel. Mater. Lett. 177, 76 (2016).

95. C.K. Chua and M. Pumera: Chemical reduction of graphene oxide: A synthetic chemistry viewpoint. Chem. Soc. Rev. 43, 291 (2014).

96. P.M. Sudeep, T.N. Narayanan, A. Ganesan, M.M. Shaijumon, H. Yang, S. Ozden, P.K. Patra, M. Pasquali, R. Vajtai, S. Ganguli, A.K. Roy, M.R. Anantharaman, and P.M. Ajayan: Covalently interconnected three-dimensional graphene oxide solids. ACS Nano 7, 7034 (2013).

97. H. Tang, P. Gao, Z. Bao, B. Zhou, J. Shen, Y. Mei, and G. Wu: Conductive resilient graphene aerogel via magnesiothermic reduction of graphene oxide assemblies. Nano Res. 8, 1710 (2015).

98. M.A. Worsley, T.T. Pham, A.M. Yan, S.J. Shin, J.R.I. Lee, M. Bagge-Hansen, W. Mickelson, and A. Zettl: Synthesis and characterization of highly crystalline graphene aerogels. ACS Nano 8, 11013 (2014).

99. Y. Cheng, S. Zhou, P. Hu, G. Zhao, Y. Li, X. Zhang, and W. Han: Enhanced mechanical, thermal, and electric properties of graphene aerogels via supercritical ethanol drying and hightemperature thermal reduction. Sci. Rep. 7, 1439 (2017).

100. H. Hu, Z. Zhao, W. Wan, Y. Gogotsi, and J. Qiu: Ultralight and highly compressible graphene aerogels. Adv. Mater. 25, 2219 (2013).

101. H.Y. Sun, Z. Xu, and C. Gao: Multifunctional, ultra-flyweight, synergistically assembled carbon aerogels. Adv. Mater. 25, 2554 (2013).

102. F. Zhang, J. Tang, Z. Wang, and L-C. Qin: Graphene-carbon nanotube composite aerogel for selective detection of uric acid. Chem. Phys. Lett. 590, 121 (2013).

103. Z. Sui, Q. Meng, X. Zhang, R. Ma, and B. Cao: Green synthesis of carbon nanotube-graphene hybrid aerogels and their use as versatile agents for water purification. J. Mater. Chem. 22, 8767 (2012).

104. H. Hu, Z. Zhao, Y. Gogotsi, and J. Qiu: Compressible carbon nanotube-graphene hybrid aerogels with superhydrophobicity and superoleophilicity for oil sorption. Environ. Sci. Technol. Lett. 1, 214 (2014).

105. C. Wang, S. Yang, Q. Ma, X. Jia, and P-C. Ma: Preparation of carbon nanotubes/graphene hybrid aerogel and its application for the adsorption of organic compounds. Carbon 118, 765 (2017).

106. S. Manandhar, P.B. Roder, J.L. Hanson, M. Lim, B.E. Smith, A. Mann, and P.J. Pauzauskie: Rapid sol-gel synthesis of nanodiamond aerogel. J. Mater. Res. 29, 2905 (2014).

107. M. Mecklenburg, A. Schuchardt, Y.K. Mishra, S. Kaps, R. Adelung, A. Lotnyk, L. Kienle, and K. Schulte: Aerographite: Ultra lightweight, flexible nanowall, carbon microtube material with outstanding mechanical performance. Adv. Mater. 24, 3486 (2012).

108. O. Parlak, Y. Kumar Mishra, A. Grigoriev, M. Mecklenburg, W. Luo, S. Keene, A. Salleo, K. Schulte, R. Ahuja, R. Adelung, A.P.F. Turner, and A. Tiwari: Hierarchical aerographite nanomicrotubular tetrapodal networks based electrodes as lightweight supercapacitor. Nano Energy 34, 570 (2017).

109. S. Garlof, M. Mecklenburg, D. Smazna, Y.K. Mishra, R. Adelung, K. Schulte, and B. Fiedler: 3D carbon networks and their polymer composites: Fabrication and electromechanical investigations of neat aerographite and aerographite-based PNCs under compressive load. Carbon 111, 103 (2017).

110. K. Hirahara, K. Hiraishi, K. Imadate, Z. Xu, Y. Hirota, and N. Nishiyama: Ultra-flexible spiked-shell microparticles of aerographite. Carbon 118, 607 (2017).

111. S. Chandrasekaran, W.V. Liebig, M. Mecklenburg, B. Fiedler, D. Smazna, R. Adelung, and K. Schulte: Fracture, failure and compression behaviour of a 3D interconnected carbon aerogel (aerographite) epoxy composite. Compos. Sci. Technol. 122, 50 (2016).

112. D.A. Lindquist, T.T. Borek, S.J. Kramer, C.K. Narula, G. Johnston, R. Schaeffer, D.M. Smith, and R.T. Paine: Formation and pore structure of boron nitride aerogels. J. Am. Ceram. Soc. 73, 757 (1990).

113. E. Friederich and L. Sittig: Herstellung und Eigenschaften von Nitriden. Z. Anorg. Allg. Chem. 143, 293 (1925).

114. R.T. Paine and C.K. Narula: Synthetic routes to boron nitride. Chem. Rev. 90, 73 (1990).

115. W-Q. Han, R. Brutchey, T.D. Tilley, and A. Zettl: Activated boron nitride derived from activated carbon. Nano Lett. 4, 173 (2004).

116. T. Pham, A.P. Goldstein, J.P. Lewicki, S.O. Kucheyev, C. Wang, T.P. Russell, M.A. Worsley, L. Woo, W. Mickelson, and A. Zettl: Nanoscale structure and superhydrophobicity of $s p^{2}$ bonded boron nitride aerogels. Nanoscale 7, 10449 (2015).

117. A. Harley-Trochimczyk, T. Pham, J. Chang, E. Chen, M.A. Worsley, A. Zettl, W. Mickelson, and R. Maboudian: Platinum nanoparticle loading of boron nitride aerogel and its use 
as a novel material for low-power catalytic gas sensing. $A d v$ Funct. Mater. 26, 433 (2016).

118. Y. Song, B. Li, S. Yang, G. Ding, C. Zhang, and X. Xie: Ultralight boron nitride aerogels via template-assisted chemical vapor deposition. Sci. Rep. 5, 10337 (2015).

119. W. Lei, V.N. Mochalin, D. Liu, S. Qin, Y. Gogotsi, and Y. Chen: Boron nitride colloidal solutions, ultralight aerogels and freestanding membranes through one-step exfoliation and functionalization. Nat. Commun. 6, 8849 (2015).

120. H. Liu, Y. Du, Y. Deng, and P.D. Ye: Semiconducting black phosphorus: Synthesis, transport properties and electronic applications. Chem. Soc. Rev. 44, 2732 (2015)

121. S. Lin, Y. Chui, Y. Li, and S.P. Lau: Liquid-phase exfoliation of black phosphorus and its applications. FlatChem 2, 15 (2017).

122. A.H. Woomer, T.W. Farnsworth, J. Hu, R.A. Wells, C.L. Donley, and S.C. Warren: Phosphorene: Synthesis, scaleup, and quantitative optical spectroscopy. ACS Nano 9, 8869 (2015).

123. C. Xing, G. Jing, X. Liang, M. Qiu, Z. Li, R. Cao, X. Li, D. Fan, and H. Zhang: Graphene oxide/black phosphorus nanoflake aerogels with robust thermo-stability and significantly enhanced photothermal properties in air. Nanoscale 9, 8096 (2017).

124. W. Wan, L. Li, Z. Zhao, H. Hu, X. Hao, D.A. Winkler, L. Xi, T.C. Hughes, and J. Qiu: Ultrafast fabrication of covalently cross-linked multifunctional graphene oxide monoliths. Adv. Funct. Mater. 24, 4915 (2014).

125. Q.H. Wang, K. Kalantar-Zadeh, A. Kis, J.N. Coleman, and M.S. Strano: Electronics and optoelectronics of two-dimensional transition metal dichalcogenides. Nat. Nanotechnol. 7, 699 (2012).

126. M.S. Xu, T. Liang, M.M. Shi, and H.Z. Chen: Graphene-like two-dimensional materials. Chem. Rev. 113, 3766 (2013).

127. E.O. Ortiz-Quiles and C.R. Cabrera: Exfoliated molybdenum disulfide for dye sensitized solar cells. FlatChem 2, 1 (2017).

128. T. Gacoin, L. Malier, and J-P. Boilot: New transparent chalcogenide materials using a sol-gel process. Chem. Mater. 9, 1502 (1997).

129. A. Eychmüller: Aerogels from semiconductor nanomaterials. Angew. Chem., Int. Ed. 44, 4839 (2005).

130. I.U. Arachchige and S.L. Brock: Sol-gel methods for the assembly of metal chalcogenide quantum dots. Acc. Chem. Res. 40, 801 (2007)

131. S. Bag, P.N. Trikalitis, P.J. Chupas, G.S. Armatas, and M.G. Kanatzidis: Porous semiconducting gels and aerogels from chalcogenide clusters. Science 317, 490 (2007).

132. F. Rechberger and M. Niederberger: Synthesis of aerogels: From molecular routes to 3-dimensional nanoparticle assembly. Nanoscale Horiz. 2, 6 (2017).

133. K. Shehzad, Y. Xu, C. Gao, and X. Duan: Three-dimensional macro-structures of two-dimensional nanomaterials. Chem. Soc. Rev. 45, 5541 (2016).

134. J. Wu, X. Liu, L. Yan, and L. Zhang: Long-range order and preferred orientation in $\mathrm{WS}_{2}$ scaffold created by freeze casting. Mater. Lett. 196, 414 (2017).
135. Y. Zhao, X. Xie, J. Zhang, H. Liu, H-J. Ahn, K. Sun, and G. Wang: $\mathrm{MoS}_{2}$ nanosheets supported on 3D graphene aerogel as a highly efficient catalyst for hydrogen evolution. Chem.-Eur. J. 21, 15908 (2015).

136. A. Liu, L. Zhao, J. Zhang, L. Lin, and H. Wu: Solvent-assisted oxygen incorporation of vertically aligned $\mathrm{MoS}_{2}$ ultrathin nanosheets decorated on reduced graphene oxide for improved electrocatalytic hydrogen evolution. ACS Appl. Mater. Interfaces 8, 25210 (2016).

137. L. Jiang, B. Lin, X. Li, X. Song, H. Xia, L. Li, and H. Zeng: Monolayer $\mathrm{MoS}_{2}$-graphene hybrid aerogels with controllable porosity for lithium-ion batteries with high reversible capacity. ACS Appl. Mater. Interfaces 8, 2680 (2016).

138. Y. Wang, D. Kong, W. Shi, B. Liu, G.J. Sim, Q. Ge, and H.Y. Yang: Ice templated free-standing hierarchically $\mathrm{WS}_{2} /$ CNT-rGO aerogel for high-performance rechargeable lithium and sodium ion batteries. Adv. Energy Mater. 6, 1601057 (2016).

139. H. Long, A. Harley-Trochimczyk, T. Pham, Z. Tang, T. Shi, A. Zettl, C. Carraro, M.A. Worsley, and R. Maboudian: High surface area $\mathrm{MoS}_{2} /$ graphene hybrid aerogel for ultrasensitive $\mathrm{NO}_{2}$ detection. Adv. Funct. Mater. 26, 5158 (2016).

140. T. Sun, Z. Li, X. Liu, L. Ma, J. Wang, and S. Yang: Facile construction of 3D graphene/ $\mathrm{MoS}_{2}$ composites as advanced electrode materials for supercapacitors. J. Power Sources 331, 180 (2016).

141. W.S.V. Lee, E. Peng, T.A.J. Loh, X. Huang, and J.M. Xue: Fewlayer $\mathrm{MoS}_{2}$-anchored graphene aerogel paper for free-standing electrode materials. Nanoscale 8, 8042 (2016).

142. C. Zhu, T. Liu, F. Qian, W. Chen, S. Chandrasekaran, B. Yao, Y. Song, E.B. Duoss, J.D. Kuntz, C.M. Spadaccini, M.A. Worsley, and Y. Li: 3D printed functional nanomaterials for electrochemical energy storage. Nano Today. 15, 107-120 (2017).

143. C. Zhu, T. Liu, F. Qian, T.Y-J. Han, E.B. Duoss, J.D. Kuntz, C.M. Spadaccini, M.A. Worsley, and Y. Li: Supercapacitors based on three-dimensional hierarchical graphene aerogels with periodic macropores. Nano Lett. 16, 3448 (2016).

144. Y. Lin, F. Liu, G. Casano, R. Bhavsar, I.A. Kinloch, and B. Derby: Pristine graphene aerogels by room-temperature freeze gelation. Adv. Mater. 28, 7993 (2016).

145. C. Zhu, T.Y.J. Han, E.B. Duoss, A.M. Golobic, J.D. Kuntz, C.M. Spadaccini, and M.A. Worsley: Highly compressible 3D periodic graphene aerogel microlattices. Nat. Commun. 6 (2015).

146. Q. Zhang, F. Zhang, S.P. Medarametla, H. Li, C. Zhou, and D. Lin: 3D printing of graphene aerogels. Small 12, 1702 (2016).

147. L. Qiu, J.Z. Liu, S.L.Y. Chang, Y. Wu, and D. Li: Biomimetic superelastic graphene-based cellular monoliths. Nat. Commun. 3, 1241 (2012).

148. T. Liu, M. Huang, X. Li, C. Wang, C-X. Gui, and Z-Z. Yu: Highly compressible anisotropic graphene aerogels fabricated by directional freezing for efficient absorption of organic liquids. Carbon 100, 456 (2016).

\section{Supplementary Material}

To view supplementary material for this article, please visit https://doi.org/10.1557/jmr.2017.411. 